\title{
Monitoring and Optimization of the Machining Process When Turning of AISI 316L Based on RSM- DF and ANN-NGSAII Approaches.
}

oussama benkhelifa

Frères Mentouri University

Mourad Nouioua

Mechanics Research Centre https://orcid.org/0000-0003-0439-2112

Abdelhakim Cherfia ( $\nabla$ cherfia_abdelhakim@yahoo.fr)

Frères Mentouri University

\section{Research Article}

Keywords: ANN, Machining, ANOVA, Tool wear, Cutting temperature, Desirability Function, NSGA II.

Posted Date: January 25th, 2022

DOI: https://doi.org/10.21203/rs.3.rs-1276720/v1

License: (c) (i) This work is licensed under a Creative Commons Attribution 4.0 International License.

Read Full License 


\title{
Proposed Title: Monitoring and optimization of the machining process when turning of AISI 316 based on RSM-DF and ANN-NGSAII approaches.
}

\section{Oussama Benkhelifa ${ }^{1}$. Mourad Nouioua ${ }^{2}$. Abdelhakim Cherfia ${ }^{1}$}

Mail: oussamabenkhelifa61@gmail.com

1: Mechanical Engineering Departement, Mechanical research Laboratory, Frères Mentouri University, Constantine 1. 25000 Constantine, Algeria.

2: Mechanics Research Centre, Po, Box 73B, 25000 Constantine, Algeria.

\begin{abstract}
Stainless steels have gained much attention to be one of the most widely used metallic due to their high mechanical properties, corrosion resistance in moderately corrosive environments and their ability to use in biomedical devices, food industry and implants in human body. However, owing to their low thermal conductivity and high ductility, these materials are classed as materials difficult to machine. Therefore, the object of this experimental study is to investigate the effect of cutting parameters such as cutting speed $(\mathrm{Vc})$, feed rate (f) and depth of cut (ap) on the machining outputs including surface roughness (Ra), cutting temperature $\left(\mathrm{T}_{\mathrm{C}}\right)$ and tool flank wear $\left(\mathrm{V}_{\mathrm{B}}\right)$ during dry turning of AISI 316L using coated carbide insert TP2501. The experiments were conducted according to Taguchi $\mathrm{L}_{27}$ orthogonal array parameter design, response surface methodology (RSM) and artificial neural network (ANN) have been used. Statistical analysis revealed that the feed rate affected for surface roughness, depth of cut the dominant factor impacted for cutting temperature, and tool flank wear mainly influenced by Vc, f and ap, respectively. The prediction results obtained by ANN and RSM models showed a good agreement with experimental data. However, ANN models proved the capability to provide more accurate results compared to RSM models. According to optimization analysis based on desirability function (DF) and non-dominated sorting genetic algorithm (NSGA II), DF results were determined to acquire high machined part quality.
\end{abstract}

Keywords: ANN, Machining, ANOVA, Tool wear, Cutting temperature, Desirability Function, NSGA II. 


\section{Nomenclature}

$\begin{array}{llll}\text { AISI: } & \text { American Iron and Steel } & \text { F-value: } & \text { Variance ratio } \\ \text { Institute } & & \text { P-value: } & \text { Probability of significance } \\ \text { Vc: } & \text { Cutting speed }(\mathrm{m} / \mathrm{min}) & \mathrm{R}^{2}: & \text { Determination coefficient } \\ \text { ap: } & \text { Depth of cut }(\mathrm{mm}) & \mathrm{R}: & \text { Correlation coefficient } \\ \mathrm{f}: & \text { Feed rate }(\mathrm{mm} / \mathrm{rev}) & \text { RSME: } & \text { Root Mean Square Error } \\ \text { Ra: } & \text { Arithmetic mean Roughness } & \text { ANN: } & \text { Artificial Neural Network } \\ (\mu \mathrm{m}) & \text { RSM: } & \text { Response Surface } \\ \mathrm{V}_{\mathrm{B}}: & \text { Tool wear }(\mathrm{mm}) & \text { Methodology } \\ \mathrm{T} \text { : } & \text { Cutting temperature }\left(\mathrm{C}^{\circ}\right) & \text { ANOVA: } & \text { Analysis of Variance } \\ \text { MS: } & \text { Mean squares } & \text { NSGA II: } & \text { Non-dominated Sorting } \\ \text { SS: } & \text { Sum of squares } & \text { Genetic Algorithm II } \\ \text { DF: } & \text { Degree of freedom } & \end{array}$

\section{Introduction}

In the present day, manufacturing industries are responsible for ensuring the consumer increasing demands on the products quality in the required quantity and in turn to obtain less expensive products in the fastest way possible. The workpieces quality is influenced by various parameters such as surface quality, tool wear and thermal resistance in aggressive environments. Therefore, the development of the machining of hard to cut materials such as AISI 316L become an absolute necessity in addition to the diversity of their applications.

The surface quality is mainly related to the surface finish and integrity obtained after machining, and its value is an important factor in evaluating machining accuracy, also imposes one of the most critical constraints for the selection of machines and cutting parameters in the planning process, the improvement of surface quality can be hindered by tool wear, cutting temperature, resistance of the tool against thermal and mechanical loads should be taken into consideration. Looking from this aspect, an ideal tool should possess the 
properties of good wear and thermal resistance, high mechanical strength and high thermal stability. Many researchers have studied the influence of cutting parameters on AISI stainless steel on machining outputs.

Touggui et al. ${ }^{[1]}$ used the Taguchi method to minimize some response parameters including surface roughness, tangential cutting force and cutting power in dry turning of AISI 316L with a cermet tool. The authors highlighted that the surface finish mainly affected by the feed rate, consequently the increase or decrease of surface roughness can be interpreted by the generation of helical grooves causing by the relative motion between work-piece and tool. Nur et al. ${ }^{[2]}$ conducted a study using coated carbide insert to machine AISI 316L under dry turning condition. The authors discussed machining parameters effects on surface roughness and cutting forces based on RSM method. Their results denoted that the feed rate has significant influence on surface roughness and cutting forces. In a recent study. Martowibowo [3] investigated the impact of certain cutting parameters on machining outputs under the dry turning process of AISI 316L, the author found that feed rate and depth of cut have a major impact on Surface roughness.

Akbar et al. ${ }^{[4]}$ investigated the effect of cutting parameters on temperature and tool life during turning AISI 316L. the author found that with high Vc, f, and depth of cuts the cross section of ships increase which led to increase the maximum temperature and the tool wear cause a decrease of tool life. Also, Singh and Sinha ${ }^{[5]}$ discussed the effects of cutting parameters (Vc, f, ap, and nose radius) on cutting force, tool flank wear and centerline mean surface roughness during dry turning of bio-implant steel (AISI 316L) using coated carbide cutting tool. The tool flank wear was found directly proportional to the depth of cut at higher values of nose radius and depth of cut and constant at lower levels. The reasons behind this possibly are the increased contact length and tool nose radius, which enhances the area of contact between the workpiece and tool. This raised the temperature sufficiently at the tool cutting edge.

Rodríguez et al. ${ }^{[6]}$ studied the variation by cutting parameters of the during the machining of the AISI 304, AISI 316L and AISI 420. Results showed that the cutting temperature increases when the values of cutting speed, feed, depth of cut, and material maximum strength are increased and that the cutting temperature decreases with the increase of materials thermal 
conductivity, being this last variable the one that showed most influence on the cutting temperature. Sathishkumar and Rajmohan ${ }^{[7]}$ made an experimental work to optimize cutting variables to reduce surface roughness and cutting temperature, experiments have been performed by plain turning of AISI 316L stainless steel on CNC lathe under MQL setup with multi-walled carbon nanotube (MWCNT) inclusions (mixed in a specific ratio $0.20 \%$ by wt. with the cutting fluid) using carbide inserts, the author concluded that feed rate is the most influencing cutting variable on the response variables. Another research made by Zaharudin and Budin ${ }^{[8]}$. The surface finish of AISI 316L stainless steel work piece, wear rate and tool life of uncoated and coated TiCN insert in turning of stainless steel was investigated. As a results, when the cutting speed increased, the wear rate increased practically while the increment in the cutting speed caused the decreasing on the surface roughness of the work material. The author also highlighted that $\mathrm{TiCN}$ coated insert not only ensure the cutting tools is wear resistance, but also ensure that the surface quality is maintained during cutting process. Same result found by Prasad et al. ${ }^{[9]}$; it is observed that lower heat and temperatures are generated when coated inserts are employed.

In order to respond to the product requirements in manufacturing processes, it is very important to forecast the surface roughness, cutting temperature and tool flank wear. Consequently, it is necessary to search the best modeling approach of these output parameters. To obtain this objective, several approaches can be used as well as surface response methodology (RSM) and artificial neural network (ANN). RSM is considered a quick and useful modeling method for the investigation and optimization of complex processes as well as for modeling machining output parameters. Asiltürk et al. ${ }^{[10]}$ found that RSM represents a good tool for predicting surface roughness in dry turning condition of AISI 304 Austenitic Stainless Steel, with a coated carbide insert (IC3028). Galanis and Manolakos ${ }^{[11]}$ developed an empirical mathematical model with the application of RSM. their results indicate that RSM modeling can give accurate results in predicting surface roughness. Chabbi et al. ${ }^{[12]}$ established a predictive modeling and multi-response optimization of technological parameters in turning of polyoxymethylene polymer (POM C) using RSM; their results of the confirmation tests show that the developed models are effectively able to predict the output responses. RSM was also employed by Parida and Maity ${ }^{[13]}$ in their experiment to determine the cause-effect relationship between the control variables and the studied response; their 
results indicate that RSM modeling can give accurate results to predict tool wear and surface roughness when turning Monel-400.

The ANN has come up as one of the most efficient methods for empirical modeling, especially for non-linear systems, as well as for modeling of output parameters in machining areas. Das et al. ${ }^{[14]}$ used artificial neural network model for analysis and prediction the relationship between cutting parameters and surface roughness of $\mathrm{Al}-4.5 \mathrm{Cu}-1.5 \mathrm{TiC}$ Metal Matrix Composites, by its capability to detect non-linear relationships. Moreover. Sangwan et al. ${ }^{[15]}$ develops an approach for determining the optimum machining parameters leading to minimum surface roughness by integrating ANN and Genetic Algorithm (GA). The proposed ANN model results indicate a good agreement between the predicted and the experimental values. In addition, Nouioua et al. ${ }^{[16]}$ investigated the influence of cutting settings on surface roughness and tangential force, when turning of X210Cr12 steel using coated carbide insert with various nose radius using ANN-based multi-objective GWO algorithm, the author proved the effectiveness of the ANN-MOGWO developed approach in prediction the uncontrollable factors as the surface roughness and the cutting force, which provide the best cutting settings. Morales et al. ${ }^{[17]}$, Asiltürk and Çunkaş ${ }^{[18]}$, Kara et al. ${ }^{[19]}$ used various models to predict outputs using Multiple regression methods and ANN Methods. Results showed that the ANN models were the most desirable method compared to the multiple regression method in terms of accuracy.

As for the comparison between surface response methodology and artificial neural network approaches. Several researches discuss the accuracy and capability of RSM and ANN. Nouioua et al. ${ }^{[20]}$, Kilickap et al. ${ }^{[21]}$, Zerti et al. ${ }^{[22]}$ developed ANN and RSM models to predict outputs parameters, the authors found that artificial neural network models show better accuracy than response surface methodology with low error, which justifies the conclusion that concerns the high precision of the ANN compared to the RSM.

Based on previous literature investigations, the main objective of this research is to study the influence of cutting speed, feed rate and depth of cut on surface roughness, cutting temperature and tool wear in dry turning of AISI 316L using coated carbide insert. In order to obtain optimal turning parameters regarding the surface quality, tool wear and the toolworkpiece temperature, taguchi's design has been used to reach this objective. Furthermore, 
the analysis of variance has been adopted to summarize which parameters have a significant influence on each response. Mathematical prediction models have been developed by response surface methodology and artificial neural networks to represent the cause effect relationship between mean responses and input control variables, the DF and NSGA II algorithm were integrated for multi-objective optimization of each response in order to achieve the full control and monitoring of the turning process using accurate modeling and optimization algorithm.

\section{Experimental procedures}

The current work investigated the influence of cutting parameters on surface roughness, tool flank wear and cutting temperature in turning of AISI 316L. The experimental tests were carried out in dry condition using a TURNADO 230 conventional lathe, with a range of speed from $30 \mathrm{rpm}$ to $3000 \mathrm{rpm}$ and $7.5 \mathrm{KW}$ spindle power. The work piece material used was AISI 316L stainless steel having the dimension of $400 \mathrm{~mm} * 80 \emptyset$, its chemical composition and physical properties are presented in Tab. 1. The chosen insert was TP2501 coated carbide designed with high wear resistance and mainly used for turning stainless steels. Its standard designation is WNMG080404-MF2, her physical properties are given in Tab. 2. The insert was clamped onto a MWLNR2525M08 tool holder and each test was achieved using new cutting edge.

Table 1. Chemical composition and physical properties of AISI 316L ${ }^{[1]}$.

\begin{tabular}{ccccccccccc}
\hline \multicolumn{10}{c}{ Chemical composition } \\
\hline C\% & Si\% & Mn\% & $\mathrm{S} \%$ & $\mathrm{Cr} \%$ & $\mathrm{Ni} \%$ & $\mathrm{Mo} \%$ & $\mathrm{Cu} \%$ & $\mathrm{Co} \%$ & $\mathrm{~V} \%$ & $\mathrm{Fe} \%$ \\
0.013 & 0.5 & 1.79 & 0.031 & 16.57 & 9.79 & 2.00 & 0.373 & 0.163 & 0.074 & 68.3 \\
\hline $\begin{array}{c}\text { Particle size } \\
\text { range } \\
11-90 \mu \mathrm{m}\end{array}$ & $\begin{array}{c}\text { Max service } \\
\text { temperature } \\
540 \mathrm{C}^{\circ}\end{array}$ & Physical properties & & & \\
\hline
\end{tabular}


Table 2. Physical properties of cutting-insert ${ }^{[23]}$.

\begin{tabular}{ccllccc}
\hline $\begin{array}{c}\text { Nose } \\
\text { radius }\end{array}$ & $\begin{array}{c}\text { Cutting edge } \\
\text { length }\end{array}$ & $\begin{array}{c}\text { Clearance } \\
\text { angle }\end{array}$ & $\begin{array}{c}\text { Rake } \\
\text { angle }\end{array}$ & $\begin{array}{c}\text { Tool } \\
\text { cutting } \\
\text { angle }\end{array}$ & $\begin{array}{c}\text { Insert } \\
\text { included } \\
\text { angle }\end{array}$ & $\begin{array}{c}\text { Hardness } \\
\text { (HRC) }\end{array}$ \\
\hline $0.4 \mathrm{~mm}$ & $8.7 \mathrm{~mm}$ & $5^{\circ}$ & $-6^{\circ}$ & $95^{\circ}$ & $80^{\circ}$ & $45-65$ \\
\hline
\end{tabular}

During each experiment, the cutting temperature was measured and recorded online using T650sc infrared camera with a pre-configured range of measurement from $100 \mathrm{C}^{\circ}$ to $650 \mathrm{C}^{\circ}$, the result is the average of the curve of each run as shown in Fig. 2. Then, the surface arithmetic roughness of the machined workpiece was recorded using roughness meter PCERT-1200 after each experiment at three different point equally positioned at $120^{\circ}$ and the result is the average of these three values. Next, the tool wear measure of each cutting edge was achieved by using YF-2010 3D microscope with digital camera (accuracy of $0.003 \mathrm{~mm}$ ). The graphical summary of the experimental setup is represented in Fig. 1.
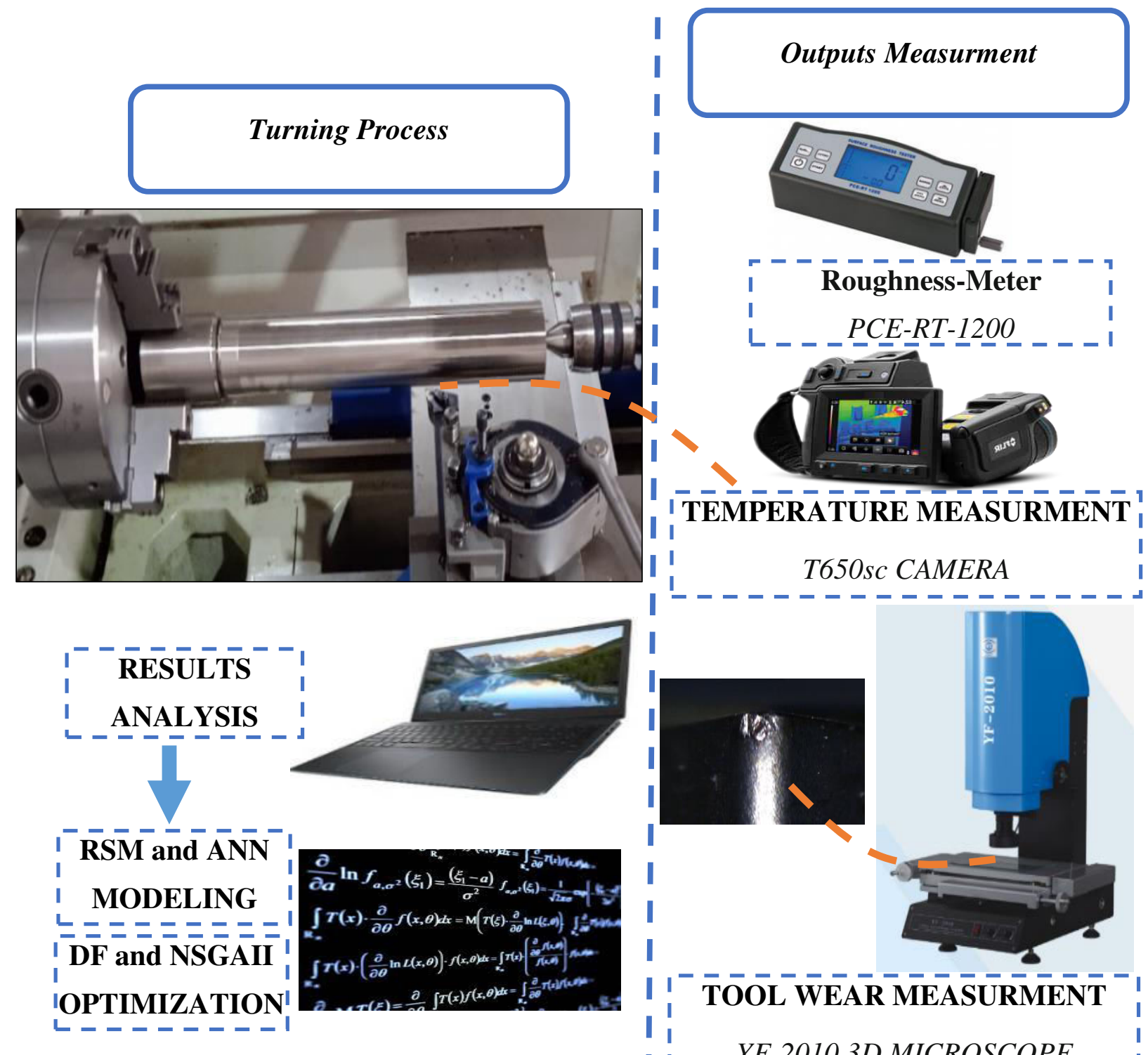
Figure 1. Experimental setup

The Taguchi design represent the perfect choice to save the experimental time and costs. The greatest advantages of this method are to decrease time, to reduce the cost and to find out significant factors in a shorter time period ${ }^{[10]}$. The cutting parameters to be studied and their levels are presented in Tab. 3 .

Table 3. Cutting parameters and their levels.

\begin{tabular}{cccc}
\hline Level & $\begin{array}{c}\text { Cutting speed } \\
\text { Vc }(\mathrm{m} / \mathrm{min})\end{array}$ & $\begin{array}{c}\text { Feed rate } \\
\mathrm{f}(\mathrm{mm} / \mathrm{rev})\end{array}$ & $\begin{array}{c}\text { depth of cut } \\
\text { ap }(\mathrm{mm})\end{array}$ \\
\hline 1 & 200 & 0.12 & 0.15 \\
2 & 300 & 0.18 & 0.30 \\
3 & 425 & 0.24 & 0.45 \\
\hline
\end{tabular}

\section{Results and discussion}

Using the full factorial experimental Taguchi design $\mathrm{L}_{27}$ ( 3 parameters with 3 levels), created by all possible combinations of cutting parameters, the corresponding experimental results of the surface roughness, cutting temperature and tool flank wear are shown in Fig. 2 and given in Tab. 4. In this study, the analysis of variance (ANOVA) method was calculated on each model to determine the significance of the model itself and its coefficients. For each machining response, an empirical model was developed using RSM and ANN. The RSM and ANN approaches were used in order to predict the cutting settings and compared in terms of the predicted data and their coefficient of determination $\left(\mathrm{R}^{2}\right)$. Finally, in order to achieve the optimal cutting parameters. The multi-objective optimization using DF and NSGAII were adopted and compared. The Fig. 3 displays the flow chart pertaining to the analysis procedure. 


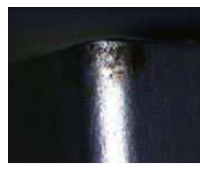

1

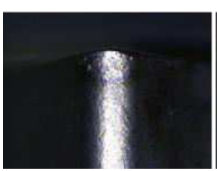

8

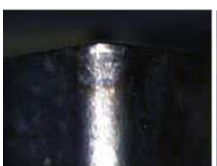

15

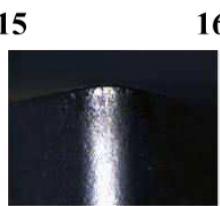

22

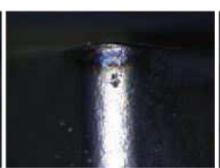

9

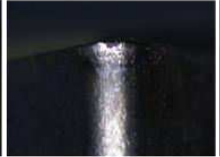

10
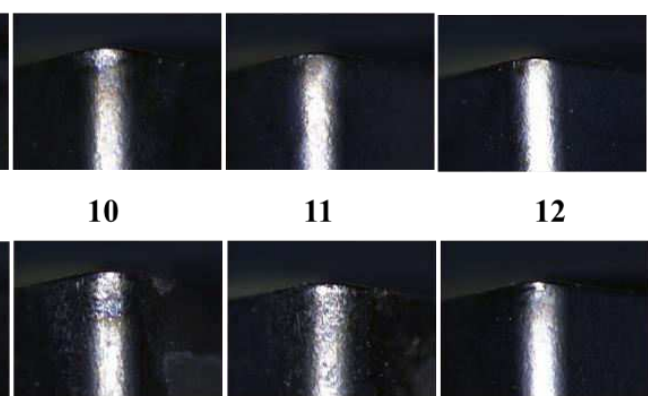

12
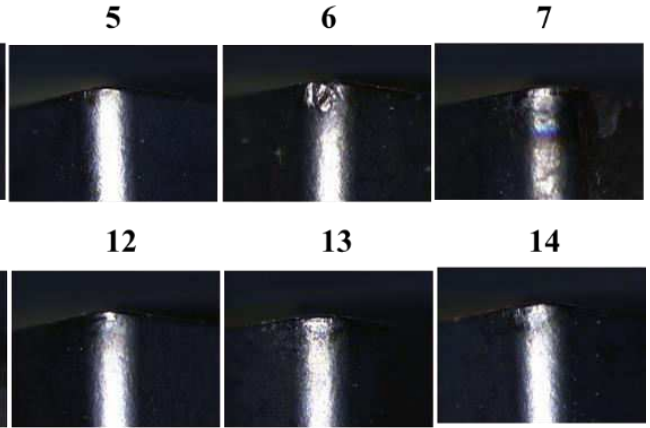

13

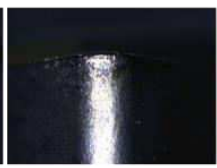

14

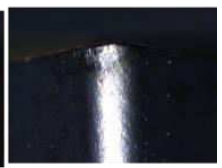

18

19

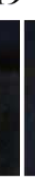

25

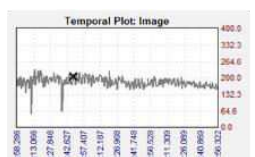

(8)

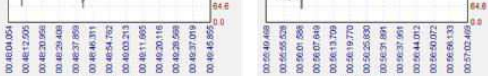

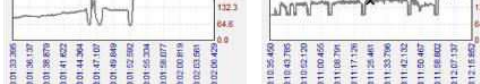

1.80
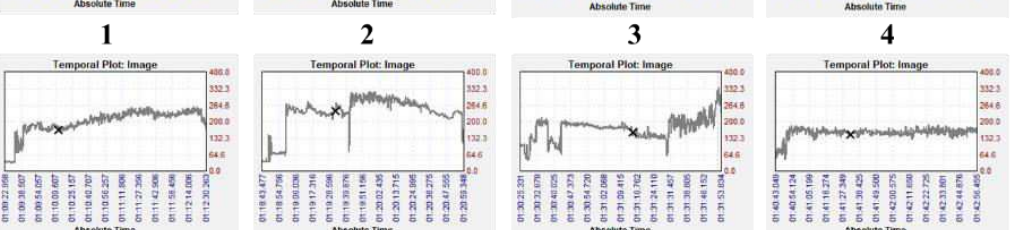

5.
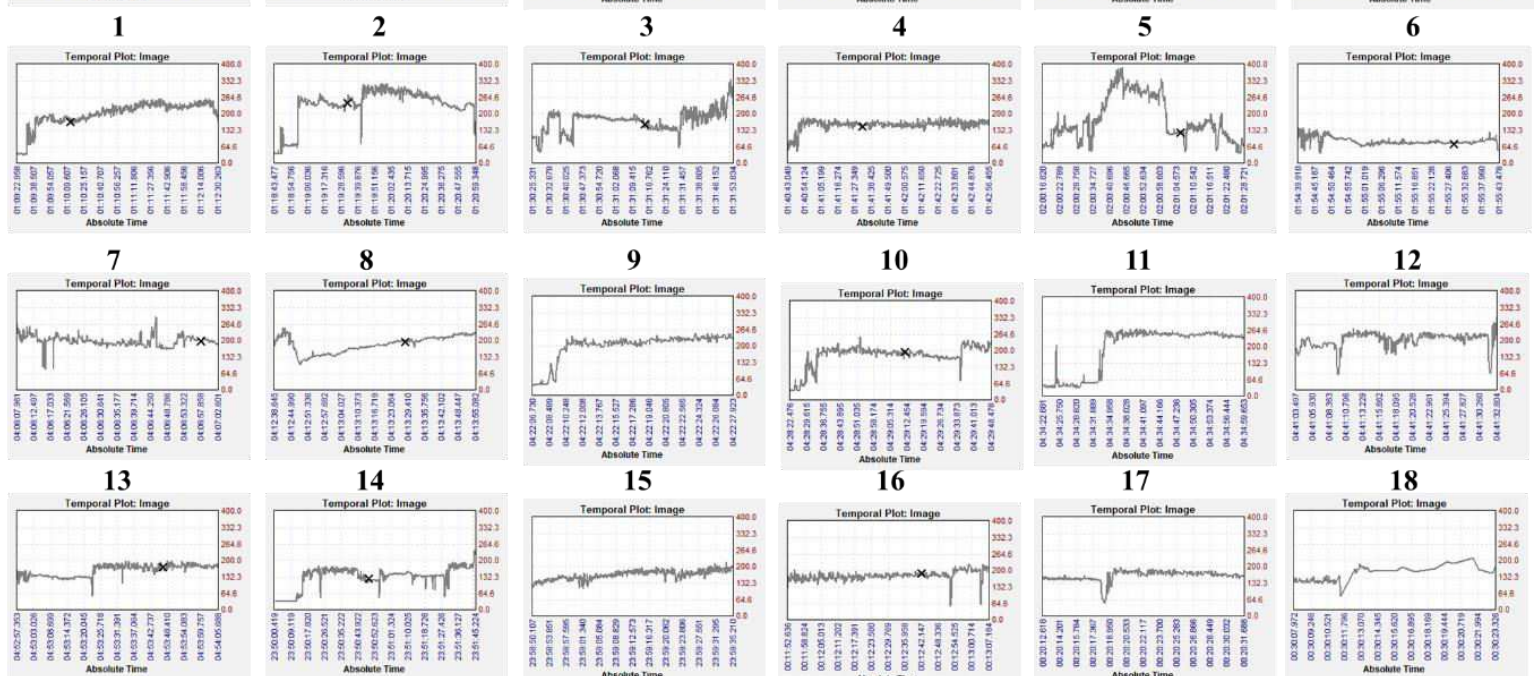

12
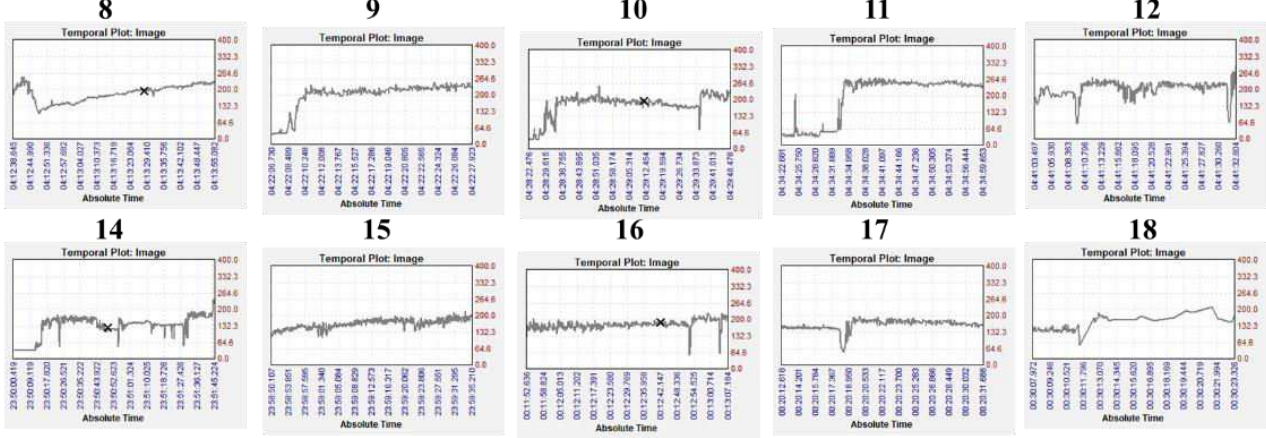

19

20

21

22

23

24 


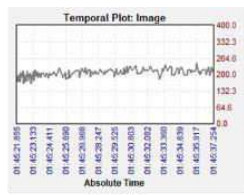

25

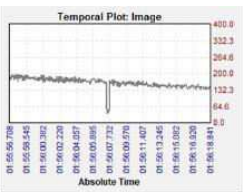

26

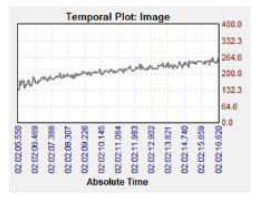

27

Figure 2. Tool flank wear and cutting temperature experimental results

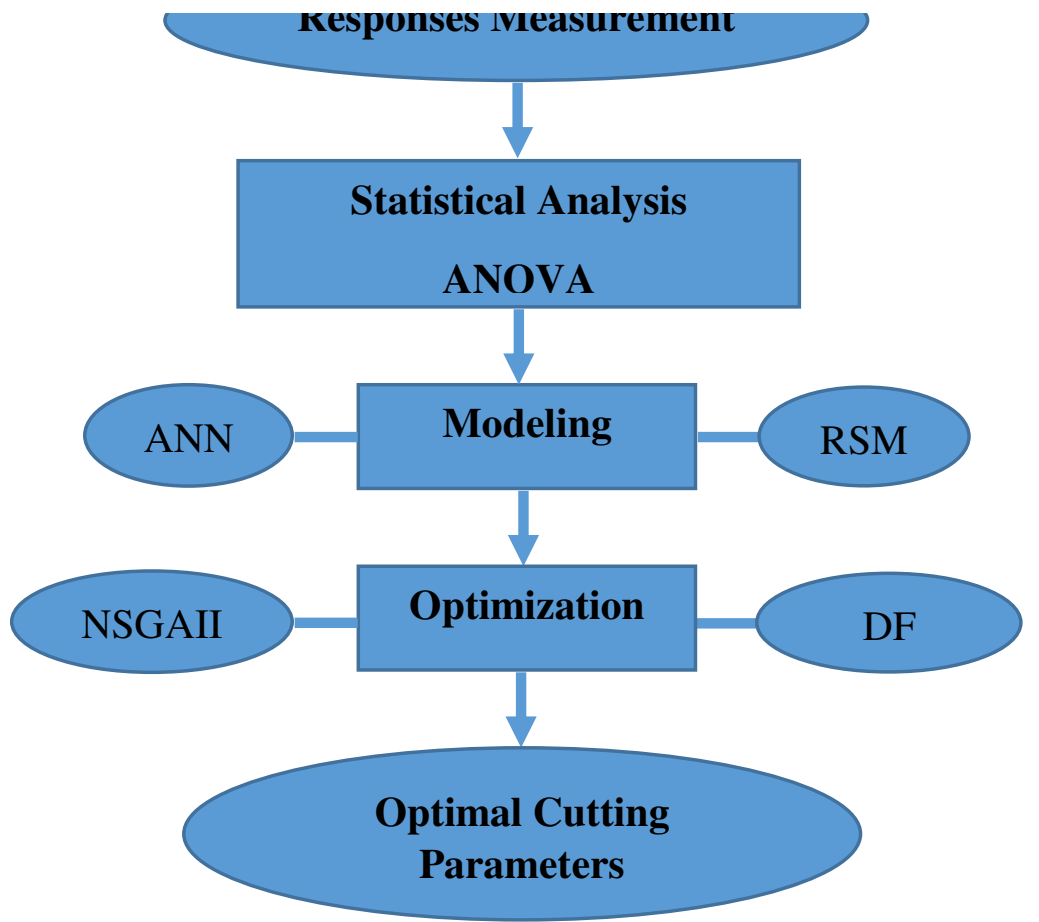

Figure 3. flow chart of the analysis methodology.

Table 4. Experimental results

\begin{tabular}{cccc|ccc}
\hline & $\begin{array}{c}\mathrm{Vc} \\
(\mathrm{m} / \mathrm{min})\end{array}$ & $\begin{array}{c}\mathrm{f} \\
(\mathrm{mm} / \mathrm{rev})\end{array}$ & $\begin{array}{c}\mathrm{ap} \\
(\mathrm{mm})\end{array}$ & $\begin{array}{c}\mathrm{Ra} \\
(\mu \mathrm{m})\end{array}$ & $\begin{array}{c}\mathrm{Tc} \\
\left(\mathrm{C}^{\circ}\right)\end{array}$ & $\begin{array}{c}\mathrm{V}_{\mathrm{B}} \\
(\mathrm{mm})\end{array}$ \\
\hline 1 & 200 & 0.12 & 0.15 & 1.36 & 207.2 & 0.092 \\
2 & 200 & 0.18 & 0.15 & 2.49 & 201.534 & 0.095 \\
3 & 200 & 0.24 & 0.15 & 3.506 & 184.107 & 0.12 \\
4 & 200 & 0.12 & 0.30 & 1.3 & 231.00 & 0.107 \\
5 & 200 & 0.18 & 0.30 & 2.466 & 214.079 & 0.116 \\
6 & 200 & 0.24 & 0.30 & 3.413 & 207.307 & 0.135 \\
7 & 200 & 0.12 & 0.45 & 1.323 & 243.144 & 0.106 \\
8 & 200 & 0.18 & 0.45 & 2.083 & 265.04 & 0.112 \\
9 & 200 & 0.24 & 0.45 & 3.553 & 265.122 & 0.146
\end{tabular}




\begin{tabular}{lccc|ccc}
10 & 300 & 0.12 & 0.15 & 1.141 & 209.953 & 0.103 \\
11 & 300 & 0.18 & 0.15 & 2.266 & 199.772 & 0.109 \\
12 & 300 & 0.24 & 0.15 & 3.193 & 198.974 & 0.112 \\
13 & 300 & 0.12 & 0.30 & 1.305 & 233.844 & 0.1 \\
14 & 300 & 0.18 & 0.30 & 2.276 & 229.03 & 0.109 \\
15 & 300 & 0.24 & 0.30 & 3.44 & 222.363 & 0.121 \\
16 & 300 & 0.12 & 0.45 & 1.48 & 242.198 & 0.12 \\
17 & 300 & 0.18 & 0.45 & 2.29 & 265.88 & 0.124 \\
18 & 300 & 0.24 & 0.45 & 3.56 & 266.486 & 0.156 \\
19 & 425 & 0.12 & 0.15 & 1.126 & 195.373 & 0.098 \\
20 & 425 & 0.18 & 0.15 & 1.93 & 201.272 & 0.115 \\
21 & 425 & 0.24 & 0.15 & 3.16 & 200.703 & 0.185 \\
22 & 425 & 0.12 & 0.30 & 1.243 & 213.754 & 0.127 \\
23 & 425 & 0.18 & 0.30 & 2.56 & 220.728 & 0.159 \\
24 & 425 & 0.24 & 0.30 & 3.12 & 204.034 & 0.201 \\
25 & 425 & 0.12 & 0.45 & 1.27 & 242.826 & 0.125 \\
26 & 425 & 0.18 & 0.45 & 2.218 & 265.00 & 0.167 \\
27 & 425 & 0.24 & 0.45 & 3.446 & 243.196 & 0.226 \\
\hline
\end{tabular}

\subsection{Analysis of variance (ANOVA)}

ANOVA is a great statistical method frequently used to investigate and quantify the impact of cutting parameters and their interactions on machinability concerns ${ }^{[24]}$. In order to realize this goal, the statistical index $P$-value is used to judge this signification. If $P$-value is less than 5\%, this would mean the parameter is statistically significant. The results were applied with $95 \%$ confidence interval. In this study, the analysis of the acquired results was achieved using Design Expert software.

ANOVA results for $\mathrm{Ra}, \mathrm{Tc}$ and $\mathrm{V}_{\mathrm{B}}$ are presented in Tab. 5, 6, 7 respectively. The tables show the SS, DF, MS, F-value and P-value of each factor and interaction.

\subsubsection{Surface roughness analysis}

The Tab. 5 underlined that the feed rate has the most significance on surface roughness, with 92.64\% of contribution. While other parameters (ap, $\mathrm{Vc}$ ) and their interactions have no influence on Ra. This was expected because, theoretically, surface roughness for a particular nose radius is mostly a function of the feed rate and changes with the square of the feed rate 
value $^{[25]}$. During the turning process, the generated surface is a helical furrow resulting from the tool nose shape and helicoids movement tool-workpiece generated by the machine tool. In this case, the use of large feed rate results in a worst surface roughness, because at large feeds, the distance between peaks and valleys is much more important. Further, it can be observed that, the interaction effect of all the three cutting parameters has insignificant influence on surface roughness. The results found are in good agreement with the previous researcher's works mentioned in literature review.

Table 5. Results of analysis of variance (ANOVA) for Ra

\begin{tabular}{|c|c|c|c|c|c|c|}
\hline Source & SS & DF & MS & F-value & P-value & Cont. (\%) \\
\hline Model & 20.05 & 10 & 2.00 & 93.47 & $<0.0001$ & $98.33 \%$ \\
\hline $\mathrm{Vc}$ & 0.0750 & 1 & 0.0750 & 3.50 & 0.0799 & \\
\hline $\mathrm{f}$ & 18.89 & 1 & 18.89 & 880.68 & $<0.0001$ & $92.64 \%$ \\
\hline ap & 0.0587 & 1 & 0.0587 & 2.74 & 0.1175 & \\
\hline$V c \times f$ & 0.0037 & 1 & 0.0037 & 0.1727 & 0.6833 & \\
\hline Vcxap & 0.1098 & 1 & 0.1098 & 5.12 & 0.0380 & \\
\hline fxap & 0.0030 & 1 & 0.0030 & 0.1376 & 0.7155 & \\
\hline $\mathrm{Vc}^{2}$ & 0.0066 & 1 & 0.0066 & 0.3092 & 0.5859 & \\
\hline $\mathrm{f}^{2}$ & 0.0091 & 1 & 0.0091 & 0.4254 & 0.5235 & \\
\hline $\mathrm{ap}^{2}$ & 0.0156 & 1 & 0.0156 & 0.7285 & 0.4060 & \\
\hline$V c \times f \times a p$ & 0.0055 & 1 & 0.0055 & 0.2575 & 0.6188 & \\
\hline Residual & 0.3432 & 16 & 0.0214 & & & $1.67 \%$ \\
\hline Pure Error & 0.0000 & 1 & 0.0000 & & & $0.0 \%$ \\
\hline Total & 20.39 & 26 & & & & $100 \%$ \\
\hline
\end{tabular}

\subsubsection{Tool wear analysis}

According to Tab. 6 which represent ANOVA's results for tool flank wear, it seems clearly that feed rate is the most significant factor with $30.47 \%$ of contribution, cutting speed comes second with $26.369 \%$ of contribution, followed by depth of cut with a contribution of 9.589\%. The reasons behind this possibly are the increased contact length and high cutting speed, which increase the contact area between the workpiece and tool. This raised the temperature sufficiently at the tool cutting edge. The workpiece material (AISI 316L) has very low thermal conductivity; hence, most of the temperature is to be withstood by the tool, and consequently, the tool may be got soften and worn out.

Table 6. Results of analysis of variance (ANOVA) for $V_{B}$

\begin{tabular}{lllllll} 
Source & SS & DF & MS & F-value & P-value & Cont. (\%) \\
\hline
\end{tabular}




\begin{tabular}{ccccccc}
\hline Model & 0.0269 & 10 & 0.0027 & 19.51 & $<0.0001$ & $92.12 \%$ \\
Vc & 0.0077 & 1 & 0.0077 & 55.60 & $<0.0001$ & $26.369 \%$ \\
f & 0.0089 & 1 & 0.0089 & 64.54 & $<0.0001$ & $30.47 \%$ \\
ap & 0.0028 & 1 & 0.0030 & 20.63 & 0.0003 & $9.589 \%$ \\
Vcxf & 0.0027 & 1 & 0.0026 & 19.48 & 0.0004 & $9.24 \%$ \\
Vcxap & 0.0005 & 1 & 0.0005 & 3.66 & 0.0739 & $1.71 \%$ \\
fxap & 0.0001 & 1 & 0.0001 & 0.4139 & 0.5291 & \\
Vc $^{2}$ & 0.0013 & 1 & 0.0014 & 9.55 & 0.0070 & $4.45 \%$ \\
$\mathrm{f}^{2}$ & 0.0004 & 1 & 0.0004 & 2.62 & 0.1253 & $1.369 \%$ \\
ap $^{2}$ & 0.0001 & 1 & 0.0001 & 0.5818 & 0.4567 & \\
Vcxfxap & 0.0000 & 1 & 0.0000 & 0.3302 & 0.5735 & \\
Residual & 0.0022 & 16 & 0.0001 & & & $7.53 \%$ \\
\hline Pure Error & 0.0001 & 1 & 0.0001 & & & $0.35 \%$ \\
\hline Total & 0.0292 & 26 & & & & $100 \%$ \\
\hline
\end{tabular}

\subsubsection{Cutting temperature analysis}

From the Tab. 7, the ANOVA shows that the depth of cut has the strongest influence on cutting temperature with a contribution of $78.259 \%$, this result is probably due to the fact that an increase of the depth of cut generates a higher friction between the material that will be removed and the cutting tool, this will also increase the energy in the system, generating at the same time an increase of the cutting temperature. While other parameters have a weakest impact.

Table 7. Results of analysis of variance (ANOVA) for $\mathrm{T}_{\mathrm{C}}$

\begin{tabular}{|c|c|c|c|c|c|c|}
\hline Source & SS & DF & MS & F-value & P-value & Cont. (\%) \\
\hline Model & 15578.83 & 9 & 1730.98 & 25.25 & $<0.0001$ & $93.04 \%$ \\
\hline $\mathrm{Vc}$ & 18.88 & 1 & 18.88 & 0.2755 & 0.6065 & $0.112 \%$ \\
\hline $\mathrm{f}$ & 62.17 & 1 & 62.17 & 0.9070 & 0.3543 & $0.371 \%$ \\
\hline ap & 13103.89 & 1 & 13103.89 & 191.17 & $<0.0001$ & $78.259 \%$ \\
\hline $\mathrm{Vc} \times f$ & 70.86 & 1 & 70.86 & 1.03 & 0.3235 & $0.423 \%$ \\
\hline Vcxap & 16.74 & 1 & 16.74 & 0.2442 & 0.6275 & \\
\hline fxap & 358.17 & 1 & 358.17 & 5.23 & 0.0354 & $2.139 \%$ \\
\hline $\mathrm{Vc}^{2}$ & 403.69 & 1 & 403.69 & 5.89 & 0.0266 & $2.41 \%$ \\
\hline $\mathrm{f}^{2}$ & 271.44 & 1 & 271.44 & 3.96 & 0.0629 & $1.621 \%$ \\
\hline $\mathrm{ap}^{2}$ & 344.42 & 1 & 344.42 & 5.02 & 0.0386 & $2.056 \%$ \\
\hline Residual & 1165.29 & 17 & 68.55 & & & $6.959 \%$ \\
\hline Pure Error & 0.9302 & 1 & 0.9302 & & & $0.005 \%$ \\
\hline Total & 16744.12 & 26 & & & & $100 \%$ \\
\hline
\end{tabular}

\subsubsection{Cutting temperature and tool flank wear relation}


when the contact surface between the tool and the work-piece increases, the friction in this contact area will automatically rise, causing a rapid tool flank wear and an increase of the cutting temperature, this result is very clearly presented in the Fig. 4 with five runs as an example under different cutting parameters.
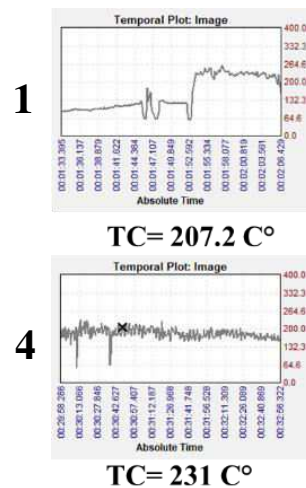

$\mathrm{TC}=231 \mathrm{C}^{\circ}$

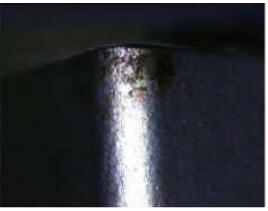

$\mathrm{VB}=0.092 \mathrm{~mm}$

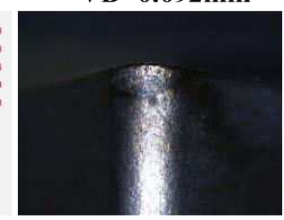

$\mathrm{VB}=0.107 \mathrm{~mm}$

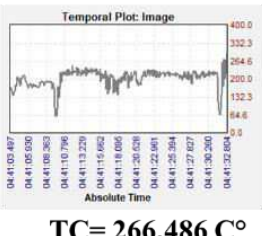

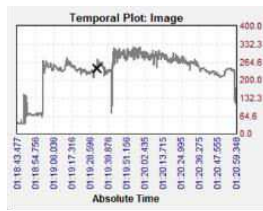

$\mathrm{TC}=265.04 \mathrm{C}^{\circ}$

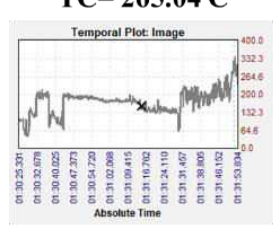

$\mathrm{TC}=265.122 \mathrm{C}^{\circ}$

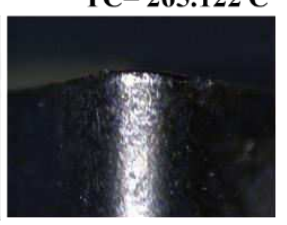

$\mathrm{VB}=0.165 \mathrm{~mm}$

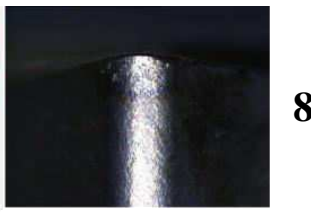

$\mathrm{VB}=\mathbf{0 . 1 1 2} \mathrm{mm}$

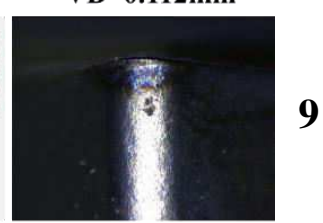

$\mathrm{VB}=0.146 \mathrm{~mm}$

18

Figure 4. Tool Flank wear and cutting temperature relation

\subsection{Modeling}

\subsubsection{RSM modeling}

In order to achieve desired results, it is needed to conduct experiments with proper planning. Therefore, response surface methodology approach is used in this work. RSM is a group of mathematical and statistical strategies for determining an appropriate functional relationship between a response of interest and a set of variables ${ }^{[26]}$. Two important models are frequently used in RSM, the linear model of Y based on first order polynomial given by Eq. 1, and the quadratic model of Y based on second order polynomial expressed by Eq. 2.

$\mathrm{Y}=a_{0}+\sum_{i=1}^{k} a_{i} X_{i}+\varepsilon$

$\mathrm{Y}=a_{0}+\sum_{i=1}^{k} a_{i} X_{i}+\sum_{\substack{i=1 \\ i \neq j}}^{k} a_{i j} X_{i} X_{j}+\sum_{i=1}^{k} a_{i i} X_{i}^{2}+\varepsilon$ 
Where, $(Y)$ is the desired output, $\left(\mathrm{X}_{\mathrm{i}}, \mathrm{X}_{\mathrm{j}}\right)$ are the independent factors, $\left(\mathrm{a}_{0}, \mathrm{a}_{\mathrm{i}}, \mathrm{a}_{\mathrm{ii}}, \mathrm{a}_{\mathrm{ij}}\right)$ are the constant term, the coefficients of the linear and quadratic terms and interactive terms respectively.

\section{Regression analysis}

In this research, estimation equations for $\mathrm{Ra}, \mathrm{V}_{\mathrm{B}}$ and $\mathrm{T}_{\mathrm{C}}$ are given by Eq. 3, 4 and 5, respectively. The coefficient of determination $\left(R^{2}\right)$ of the equations obtained with the quadratic regression models for $\mathrm{Ra}, \mathrm{V}_{\mathrm{B}}$ and $\mathrm{T}_{\mathrm{C}}$ were estimated as $98.33 \%, 92.12 \%$ and $93.04 \%$, respectively. In general, to achieve more model accuracy, the $R^{2}$ value should be between 0.8 and $1.0^{[27]}$. The closeness of the adjusted $R^{2}$ value to $R^{2}$ value indicates that the degree of the model chosen is sufficient enough to incorporate the experimental variability [28].

The mathematical model can be used to make predictions of the response for given levels of each factor. Here, the levels should be specified in the original units for each factor. This equation should not be used to determine the relative impact of each factor because the coefficients are scaled to accommodate the units of each factor and the intercept is not at the center of the design space.

$R a=-0.805541+0.001326 \times V_{c}+16.50384 \times f+1.15643 \times a p-0.011521 \times V_{c} \times$ $f+0.000895 \times V_{c} \times a p-7.28593 \times f \times a p-2.71606 \times 10^{-6} \times V_{c}^{2}+10.90892 \times f^{2}-$ $2.28420 \times a p^{2}+0.029032 \times V_{c} \times f \times a p$

$V_{B}=+0.277902-0.000975 \times V_{c}-0.980171 \times f+0.157488 \times a p+0.001604 \times V_{c} \times$ $f-0.00006 \times V_{c} \times a p-0.575824 \times f \times a p+1.21098 \times 10^{-6} \times V_{c}^{2}+2.17075 \times f^{2}-$ $0.163791 \times a p^{2}+0.002638 \times V_{c} \times f \times a p$

$T_{c}=136.60406+0.358538 \times V_{c}+338.896 \times f-109.381 \times a p+0.382971 \times V_{c} \times f-$ $0.074451 \times V_{c} \times a p+619.0608 \times f \times a p-0.00066 \times V_{c}^{2}-1876.6269 \times f^{2}+$ $338.228 \times a p^{2}$

\section{Main effect and interaction plots}

The main effect and interaction plots are represented in Fig. 5 and 6. Concerning the mean effect of the researched parameters on the output property is presented by the line graph, a higher slope mean the parameter is the most significant compared to other parameters. First, the Fig. 5.a shows that the feed rate has a higher steep slope compared to cutting speed and depth of cut. Hence, it can be stressed that the feed rate is the most significant parameter on 
surface roughness than the other parameters. Second, the tool flank wear is concerned in Fig. 5.b, both of feed rate and cutting speed present a greater steep slope compared to depth of cut. Consequently, it can be noticed that the feed and cutting speed are principal parameters that produced higher impact on $\mathrm{V}_{\mathrm{B}}$ followed by the depth of cut. Third, the cutting temperature is a function of depth of cut demonstrates a higher steep slope compared to other parameters (Fig. 5.c).

Concerning the interaction plots in Fig. 6, the interactions ( $\mathrm{x}$ ap and $\mathrm{f} x \mathrm{Vc}$ ) have significant effect on Ra, otherwise (i.e., Vc x ap) have no meaningful influence on Ra (Fig. 6.a). Whereas, the interaction ( $\mathrm{f} x \mathrm{ap}$ ) has the greatest influence on $\mathrm{V}_{\mathrm{B}}$ followed by the interaction (f $x \mathrm{Vc}$ ) (Fig. 6.b). On the contrary, the interaction (Vc $x$ ap) has insignificant effect on $V_{B}$. As what can be seen in (Fig. 6.c), the interaction (Vc $x$ ap) has significant effect on Tc compared to other interactions.

a)

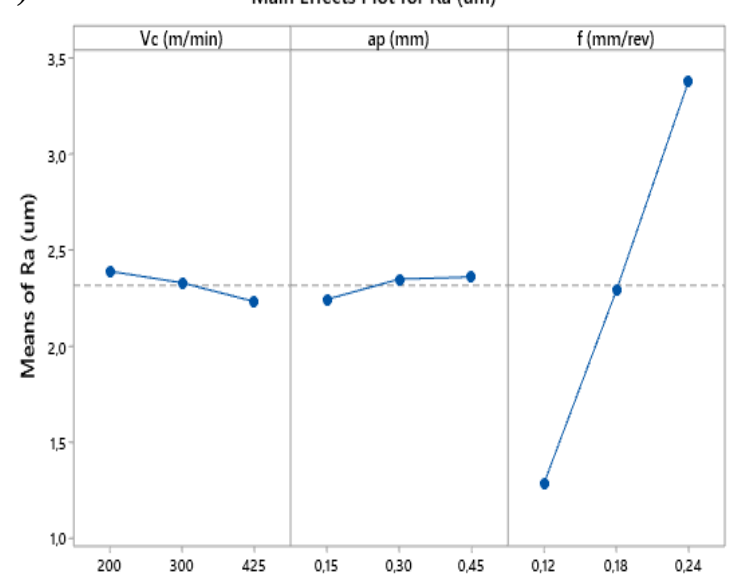

b)

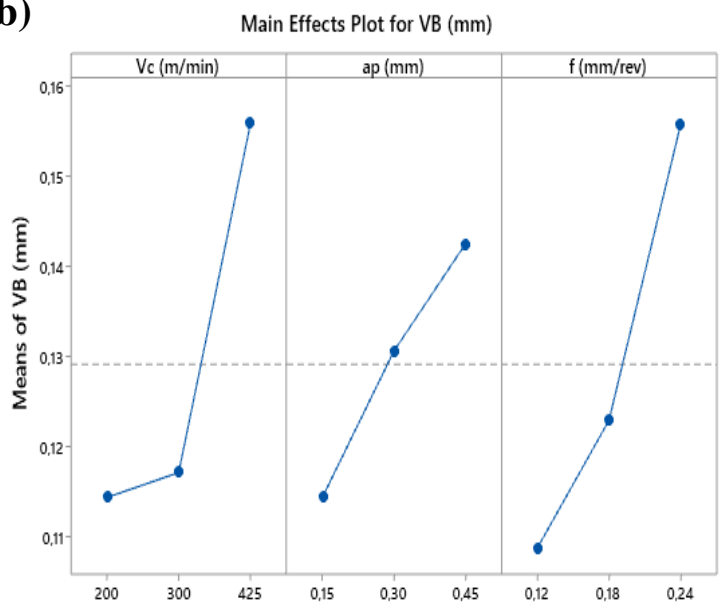

c)

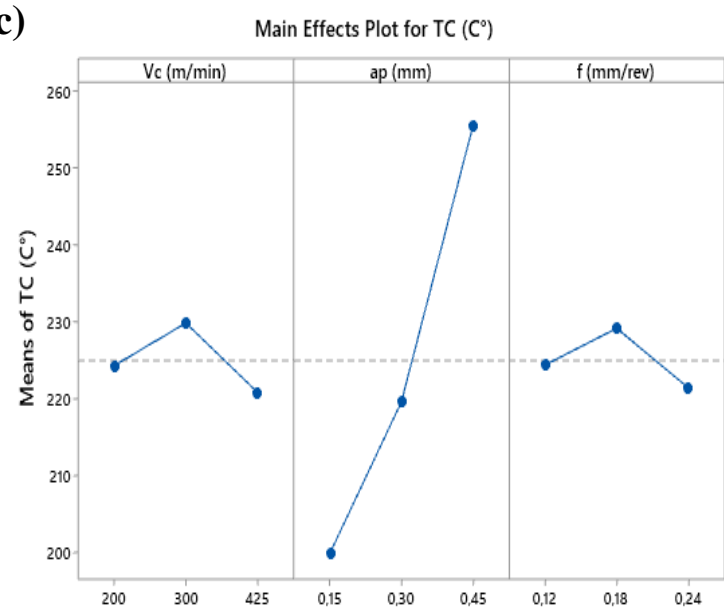


Figure 5. Main effects plot for (a)-Ra, (b)- $V_{B}$ and (c) $-T_{C}$

a)

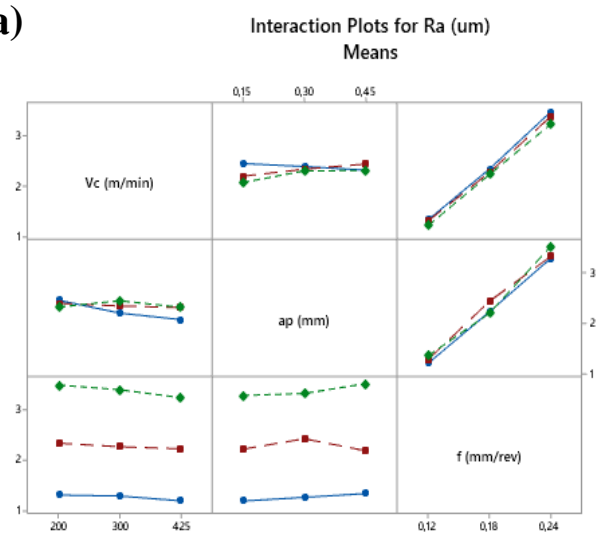

b)
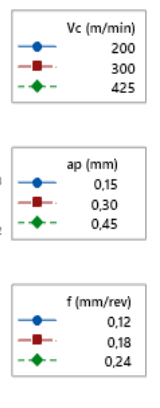

Interaction Plots for VB (mm)

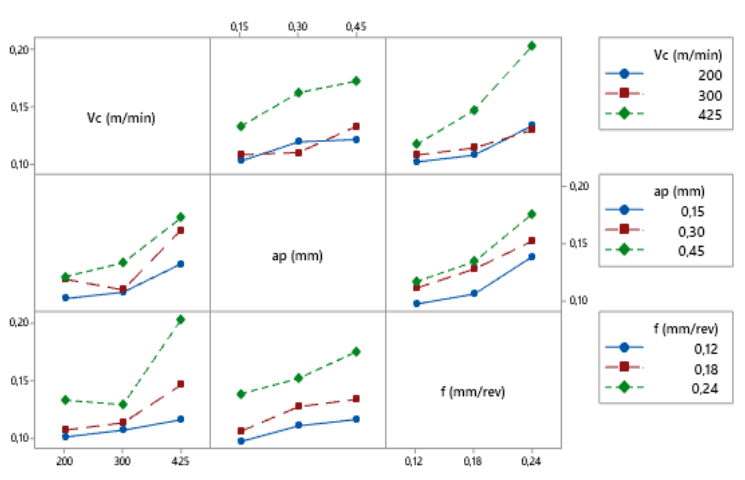

c)

Interaction Plots for TC $\left(\mathrm{C}^{\circ}\right)$

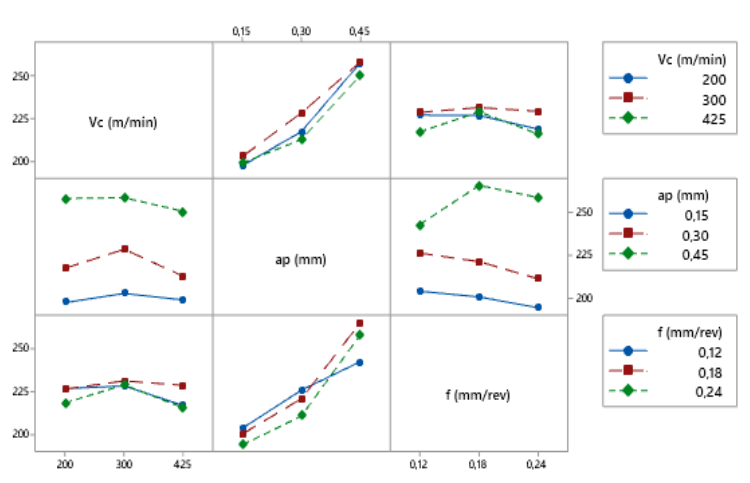

Figure 6. Interaction plot for (a)-Ra, (b)- $\mathrm{V}_{\mathrm{B}}$ and (c) $-\mathrm{T}_{\mathrm{C}}$

\section{D surface plots}

Three-dimensional response surface plots were drawn to study the effect of the input factors on surface roughness, tool flank wear and cutting temperature. These 3D plots were drawn as one of the most influencing factors was fixed at the middle level, while the other two factors are varied. 
As feed rate is the most influencing factor on surface roughness. Its effect is shown in Fig. 7.a. This figure displays that the surface roughness values will be higher when feed rate is high. It is clearly remarked that $\mathrm{Ra}$ increases three times more as the feed increases from 0.12 to $0.24 \mathrm{~mm} / \mathrm{rev}$. while the cutting depth and cutting speed do not affect the surface quality much.

As tool flank wear is greatly affected by feed rate and cutting speed, the effect of feed rate on $V_{B}$ is illustrated in Fig. 7.b. It is found that tool flank wear increases with increasing effects of both cutting speed and feed rate. $V_{B}$ increases when feed rate goes from 0.12 to $0.24 \mathrm{~mm} / \mathrm{rev}$ with an average percentage of $70 \%$. This figure also displays that the tool wear increase slightly with the increase of the depth of cut.

As cutting temperature is highly influenced by depth of cut. The Fig. 7.c present the evolution of the cutting temperature according to depth of cut, it can be remarked that $\mathrm{T}_{\mathrm{C}}$ is lowest with weakest value of depth of cut and cutting speed. Then, it increases as the depth of cut is increased from 0.15 to $0.45 \mathrm{~mm}$ with an average of $50 \mathrm{C}^{\circ}$. in the other hand, $\mathrm{T}_{\mathrm{C}}$ increases in the first part of the variation field of Vc and feed rate, and decrease in the second part. With a maximum value at middle levels.
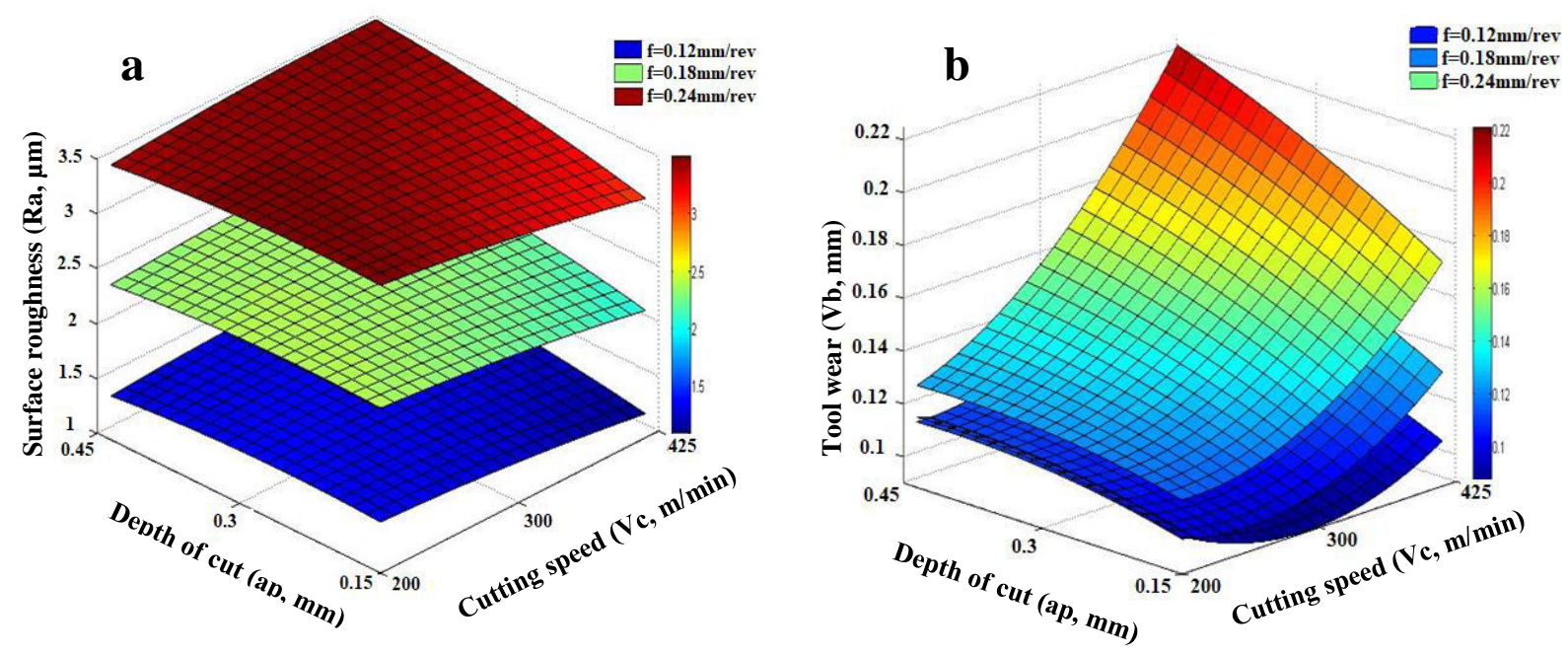


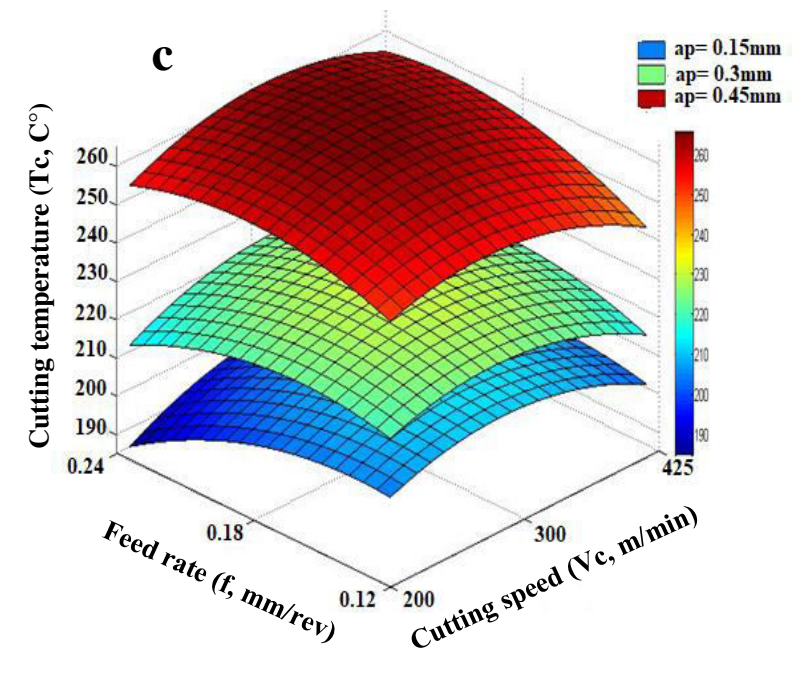

Figure 7. 3D plots for (a)-Ra, (b)- $\mathrm{V}_{\mathrm{B}}$, and (c)- $\mathrm{T}_{\mathrm{C}}$

\section{L.L.L. HIVIV IIUUEIIII}

An ANN is a data processing and modeling technique works similarly to the human brain, ANNs are very efficient on adaptation and learning and capable to model the highly nonlinear processes. for this reason, they are used as modeling tools in a number of applications $[15,16,20,22]$.

A neural network contains a number of neurons connected one other according to a specific architecture, each neuron is a mathematical function that collects, classifies information and produce an output. The information travel from the input layer to the output layer, traversing the hidden layer.

In this study, the artificial neural network was set up using the MATLAB Neural Network Toolbox. Numerous models were tested in order to determine the optimal network structure of the ANN prediction model, the most suitable activation function and the applicable training algorithm. The optimal number of neurons in the hidden layer $\mathrm{H}$ has been chosen on the basis of the correlation coefficient $(\mathrm{R})$ and the root mean square error (RSME).

The back propagation algorithm was used as a learning algorithm, the TRAINLM was utilized as training algorithm which is the fastest back propagation algorithm in the toolbox and highly recommended as the first-choice supervised algorithm (mathworks, MATLAB), 
the hyperbolic tangent sigmoid (TANSIG) transfer function was used as an activation function.

\section{Surface Roughness:}

The selected architecture of ANN was found to be a feed forward neural network with single hidden layer consisting of five nodes as shown in Fig. 8, three nodes in the input layer corresponds to the three cutting parameters ( $\mathrm{Vc}, \mathrm{f}$ and ap), and one node in the output layer. It is very important train the neural network for accurate results; less training makes the ANNs inefficient and may provide inaccurate prediction ${ }^{[20]}$.

For the chosen architecture (3-5-1). 23 tests are reserved for learning and 4 tests are arbitrary selected for validation.

Tab. 8 shows the correlation coefficient (R), the mean squared error (RMSE) values of different architecture tested to select the optimal one, with the nearest $\mathrm{R}$ to unit and the weakest RSME.

The obtained predictive model for surface roughness expressed by Eq. 6. as follow:

$R_{a}=1.105-3.606 \times H_{1}+0.128 \times H_{2}-0.147 \times H_{3}-0.794 \times H_{4}+9.026 \times H_{5}$ (6)

where $\mathrm{H} 1$ to $\mathrm{H} 5$ represent the hidden layer codes used, they expressed as follows:

$$
\begin{aligned}
& H_{1}=\tanh \left(0.0016-0.0045 \times V_{C}+6.141 \times a p+1.872 \times f\right) \\
& H_{2}=\tanh \left(3.404-0.00219 \times V_{C}-1.038 \times a p-7.306 \times f\right) \\
& H_{3}=\tanh \left(-1.136-0.000411 \times V_{C}+1.459 \times a p+2.455 \times f\right) \\
& H_{4}=\tanh \left(2.182-0.00399 \times V_{C}+2.1 \times a p-4.547 \times f\right) \\
& H_{5}=\tanh \left(-0.0575-0.0019 \times V_{C}+4.249 \times a p+0.434 \times f\right)
\end{aligned}
$$

Table 8. Performance of ANN structures of (Ra) model

\begin{tabular}{ccc}
\hline Configuration & R & RMSE \\
\hline $3-3-1$ & 0.99 & 0.005 \\
$3-4-1$ & 0.998 & 0.0019 \\
$\mathbf{3 - 5 - 1}$ & $\mathbf{0 . 9 9 6}$ & $\mathbf{0 . 0 0 0 2 8}$ \\
$3-6-1$ & 0.991 & 0.0107
\end{tabular}




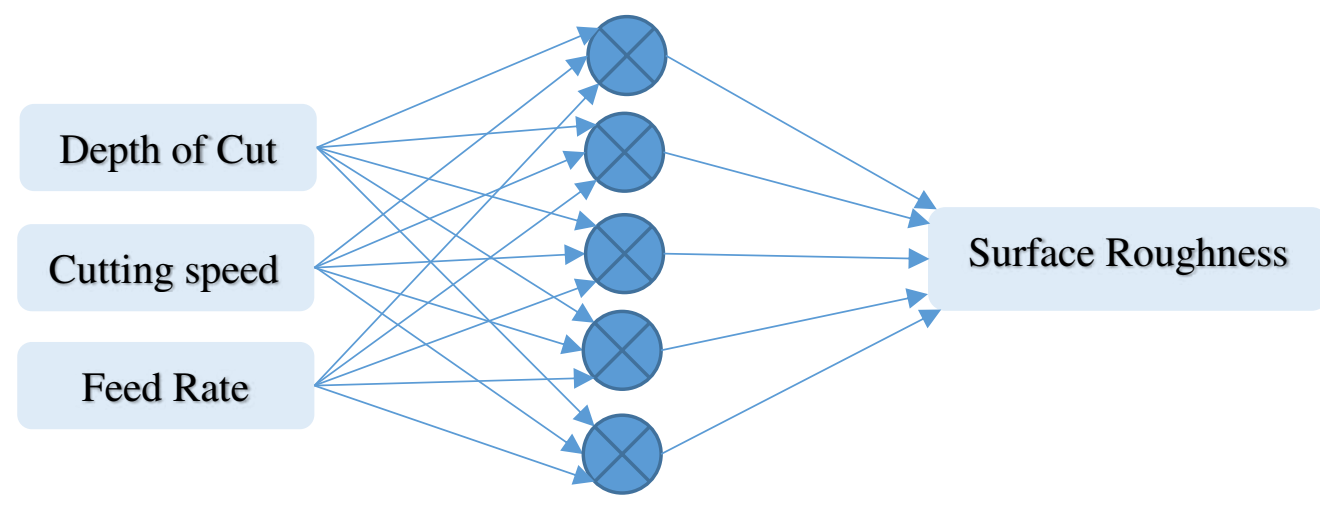

Figure 8. Neural Network architecture selected for Ra

\section{Cutting Temperature:}

The same steps are considered to model cutting temperature (Tc). The optimal structure chosen is found as (3-5-1) shown in Fig. 9. The correlation coefficient (R) and the mean squared error (RMSE) values for different architecture to chose the optimal model are shown in Tab. 9.

The developed cutting temperature ANN model is expressed as follows:

$T_{C}=176.7076-4338.312 \times H_{1}-8168 \times H_{2}-613.532 \times H_{3}+2849.086 \times H_{4}+$ $9863.184 \times \mathrm{H}_{5}$

where $\mathrm{H} 1, \ldots \mathrm{H} 5$ represent the hidden layer codes used for calculations, expressed in Eqs. (13 to 17) as follows:

$$
\begin{aligned}
& H_{1}=\tanh \left(0.0113-0.000015 \times V_{C}-0.097 \times a p+0.0273 \times f\right) \\
& H_{2}=\tanh \left(0.4278-0.00015 \times V_{C}-2.0287 \times a p-0.0664 \times f\right) \\
& H_{3}=\tanh \left(-0.0251+0.000038 \times V_{C}+0.1015 \times a p-0.0148 \times f\right) \\
& H_{4}=\tanh \left(0.4246+0.000037 \times V_{C}-0.8022 \times a p-1.3723 \times f\right) \\
& H_{5}=\tanh \left(0.238-0.000143 \times V_{C}-1.496 \times a p+0.362 \times f\right)
\end{aligned}
$$

Table 9. Performance of ANN structures of $\left(\mathrm{T}_{\mathrm{C}}\right)$ model

\begin{tabular}{ccc}
\hline Configuration & R & RMSE \\
\hline $3-3-1$ & 0.969 & 12.275 \\
$3-4-1$ & 0.986 & 20.909
\end{tabular}



3-5-1
0.97
3.507
$3-6-1$
0.947
107.925
$3-7-1$
0.97
90.334
$3-9-1$
0.9728
15.91

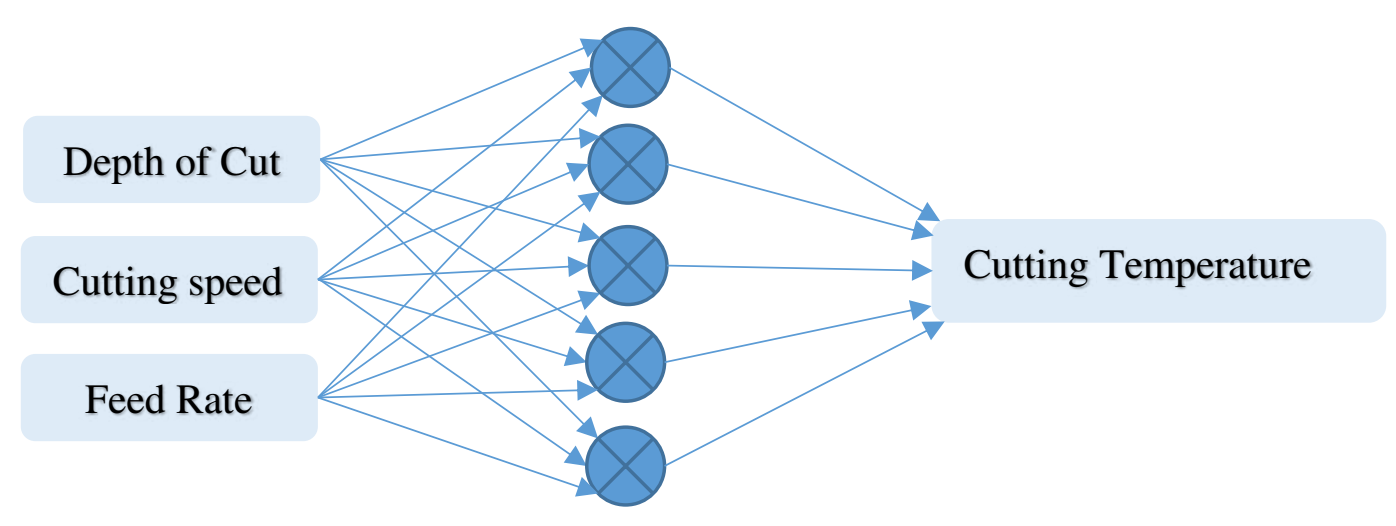

Figure 9. Neural Network architecture selected for $T_{C}$

\section{Tool wear:}

The same steps are considered to model tool wear $\left(\mathrm{V}_{\mathrm{B}}\right)$. The optimal structure chosen is found as (3-10-1) shown in Fig. 10. The correlation coefficient $(\mathrm{R})$ and the mean squared error (RMSE) values for different architecture to chose the optimal model are shown in Tab. 10.

The obtained mathematical model for prediction of $\mathrm{V}_{\mathrm{B}}$ is shown in Eq.18:

$V_{B}=0.244+0.0251 \times H_{1}-0.0158 \times H_{2}+0.00813 \times H_{3}-0.056 \times H_{4}+0.011 \times H_{5}-$ $0.038 \times H_{6}+0.034 \times H_{7}-0.0238 \times H_{8}-0.1515 \times H_{9}-0.0049 \times H_{10}$

where $\mathrm{H} 1, \ldots \mathrm{H} 10$ represent the hidden layer codes used for calculations, which are presented by Eqs. (19 to 28) as follows:

$$
\begin{aligned}
& H_{1}=\tanh \left(-3.215+0.0042 \times V_{C}+3.915 \times a p+1.475 \times f\right) \\
& H_{2}=\tanh \left(2.436+0.00281 \times V_{C}+13.2954 \times a p-5.3162 \times f\right) \\
& H_{3}=\tanh \left(3.835-0.00459 \times V_{C}-9.1413 \times a p-3.3462 \times f\right) \\
& H_{4}=\tanh \left(6.912-0.009 \times V_{C}-12.872 \times a p-3.224 \times f\right) \\
& H_{5}=\tanh \left(3.3097-0.00826 \times V_{C}-6.315 \times a p-2.9805 \times f\right) \\
& H_{6}=\tanh \left(-4.315+0.00627 \times V_{C}+12.738 \times a p+0.172 \times f\right) \\
& H_{7}=\tanh \left(-0.876+0.0113 \times V_{C}-13.787 \times a p-0.3359 \times f\right)
\end{aligned}
$$




$$
\begin{aligned}
& H_{8}=\tanh \left(3.372-0.00937 \times V_{C}-6.496 \times a p+4.154 \times f\right) \\
& H_{9}=\tanh \left(0.689+0.00203 \times V_{C}-3.6672 \times a p-0.515 \times f\right) \\
& H_{10}=\tanh \left(-0.331+0.0048 \times V_{C}-12.598 \times a p+6.5437 \times f\right)
\end{aligned}
$$

Table 10. Performance of ANN structures of $\left(V_{B}\right)$ model

\begin{tabular}{ccc}
\hline Configuration & $\mathbf{R}^{\mathbf{2}}$ & RMSE \\
\hline $3-3-1$ & 0.971 & $1.624 \mathrm{E}-5$ \\
$3-4-1$ & 0.972 & $3.203 \mathrm{E}-5$ \\
$3-5-1$ & 0.980 & $6.268 \mathrm{E}-5$ \\
$3-6-1$ & 0.943 & $1.4 \mathrm{E}-4$ \\
$3-7-1$ & 0.983 & $7.625 \mathrm{E}-6$ \\
$\mathbf{3 - 1 0 - 1}$ & $\mathbf{0 . 9 8 0}$ & $\mathbf{4 . 3 3 E - 6}$ \\
\hline
\end{tabular}

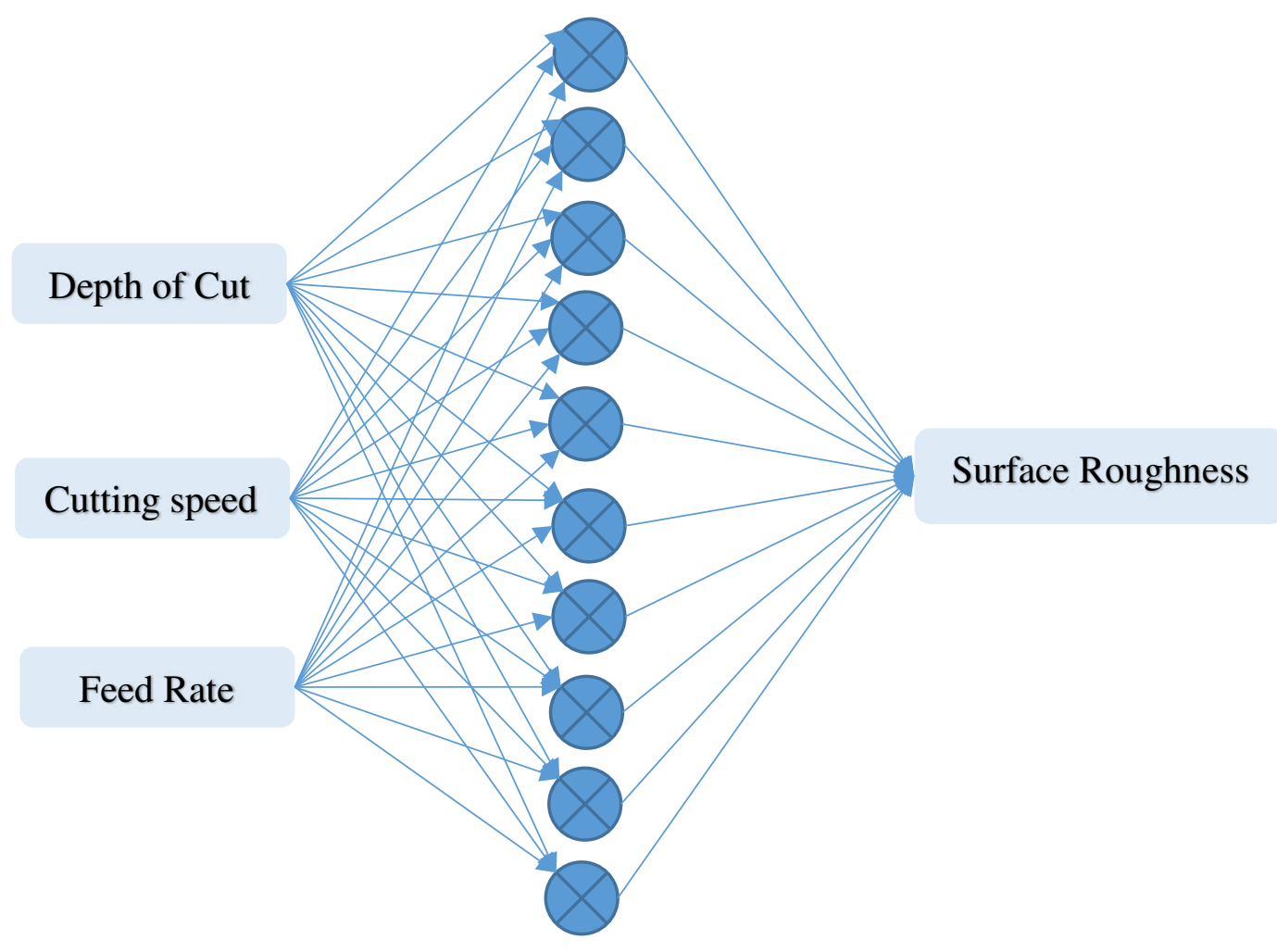

Figure 10. Neural Network architecture selected for $V_{B}$

\section{ANN performance:}

The performance capability plot of the chosen trained Artificial Neural Network (ANN) prediction model of $\mathrm{Ra}$ is presented in Fig. 6. The best validation performance (MSE) of the 
ANNs developed were found as 2.849E-4, 3.507 and 4.333E-6, respectively, for $\mathrm{Ra}_{\mathrm{C}} \mathrm{T}_{\mathrm{C}}$ and $\mathrm{V}_{\mathrm{B}}$, which can be considered as extremely satisfactory. 

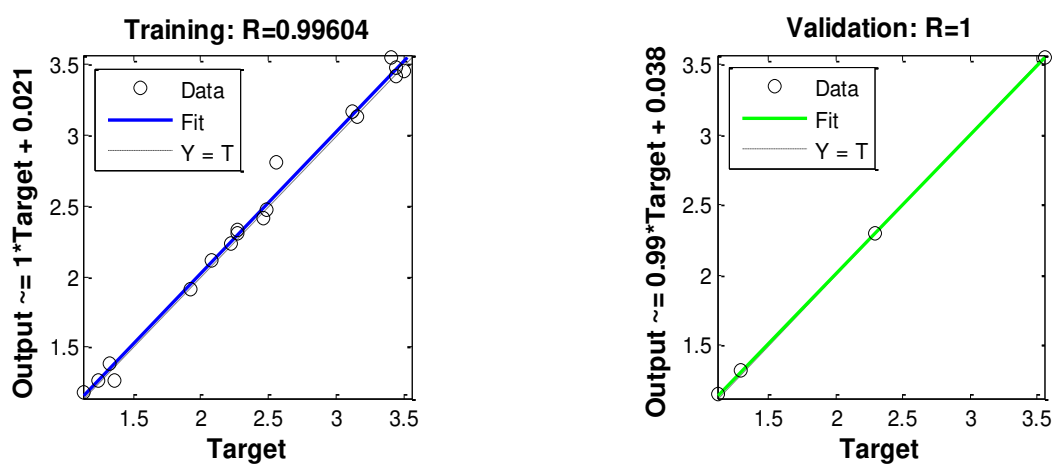

Test: R=0.99937

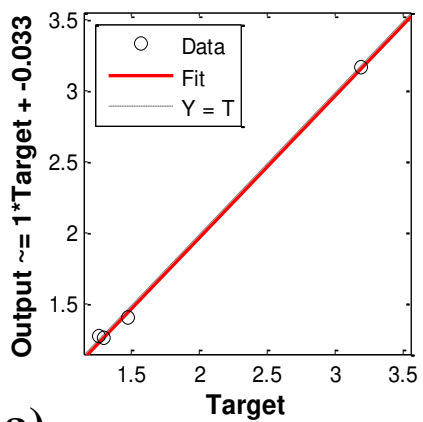

a)

Training: $\mathbf{R}=\mathbf{0} .97995$
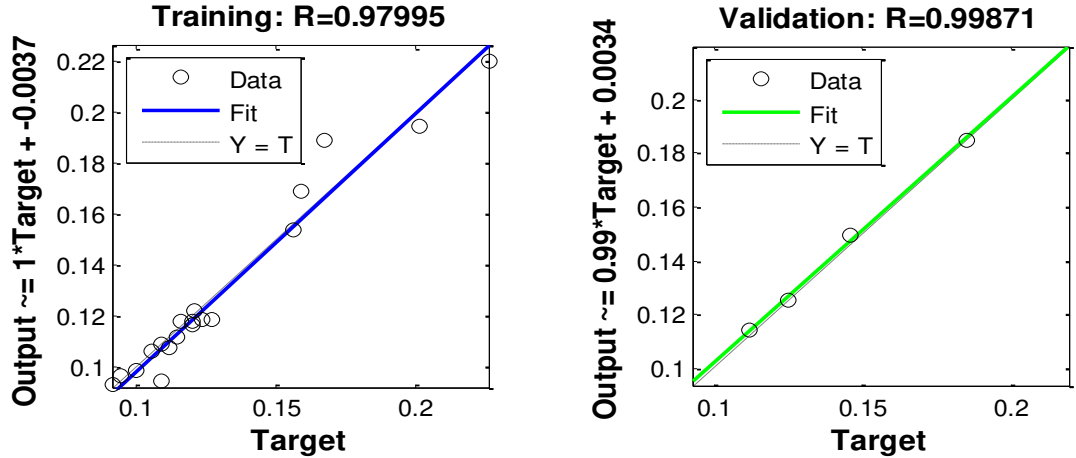

Test: $\mathbf{R}=\mathbf{0 . 9 6 8 5 4}$

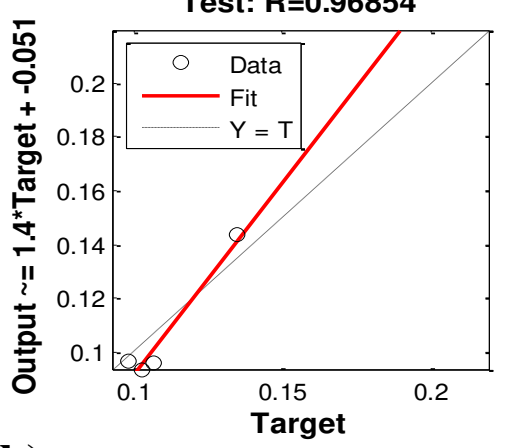

All: $\mathbf{R}=0.98008$

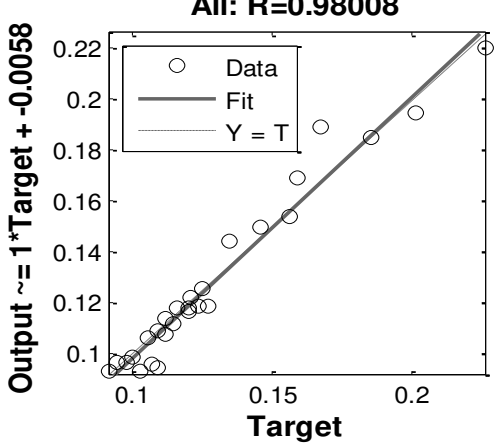

b)

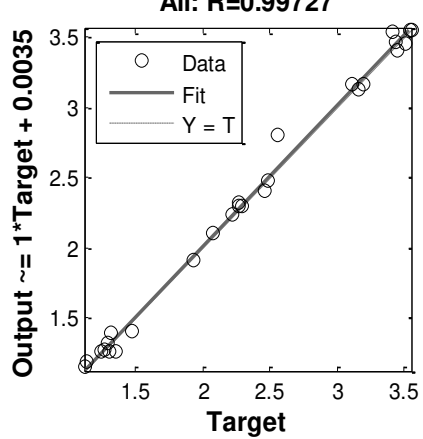



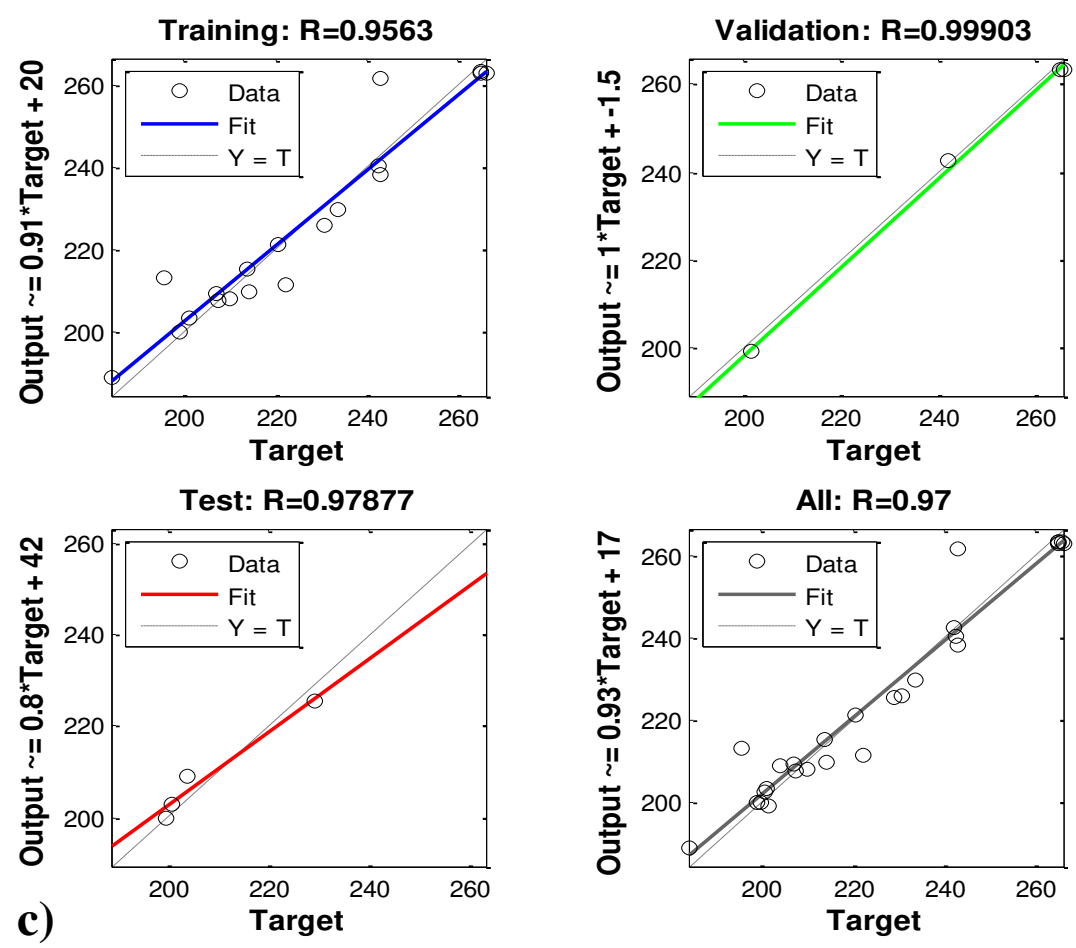

Figure 11. Correlation between predicted and experimental data using the training, validation, and test datasets for: a) surface roughness, b) cutting temperature, c) tool wear.

\subsubsection{Comparative results of ANN and RSM models}

The main advantage of RSM is its ability to investigate and quantify the impact of cutting parameters and their interactions from the coefficients in the regression model. This ability is powerful for reducing the complexity of the problem. For this raison RSM is considered a quick and useful modeling method for the investigation and optimization of complex processes as well as for modeling machining outputs. From another side, ANNs perform better than the other techniques, especially RSM when highly nonlinear behavior is considered. Also, this technique can build an efficient model using a small number of experiments; however, the technique accuracy would be better when a larger number of experiments are used for modeling.

In this study, the predictive models developed by RSM and ANN were compared on the basis of their prediction results. The results are presented in Tab. 11 and Fig. 12 a, b, c, respectively. It is well remarked that the deviations of the predicted and experimental data are smaller for ANN models compared to those of the RSM models. Which proves the robustness 
and the reliability of the ANN method. Also, the predictive models developed by RSM and ANN were compared on the basis of their prediction accuracy using their coefficient of determination $\left(\mathrm{R}^{2}\right)$ for the surface roughness, cutting temperature and tool wear RSM models are 0.9833, 0.9304 and 0.9212 and their values for ANN models are 0.996, 0.97, and 0.98, respectively. This can also clarify the capability of ANN models in providing more accurate results than those predicted by RSM.

a)

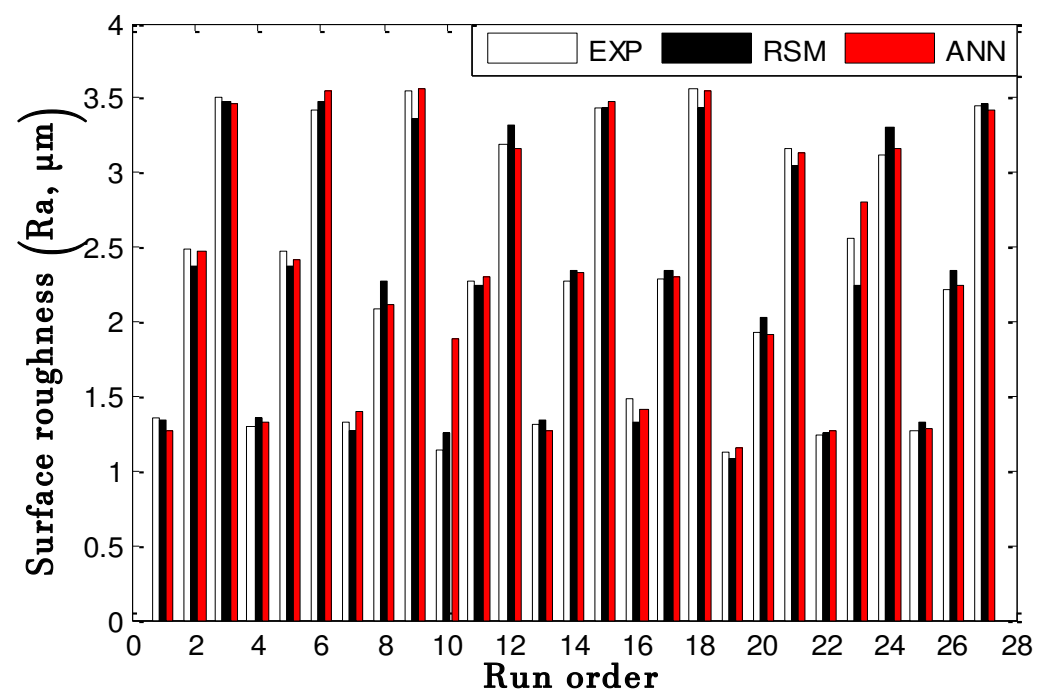

b)

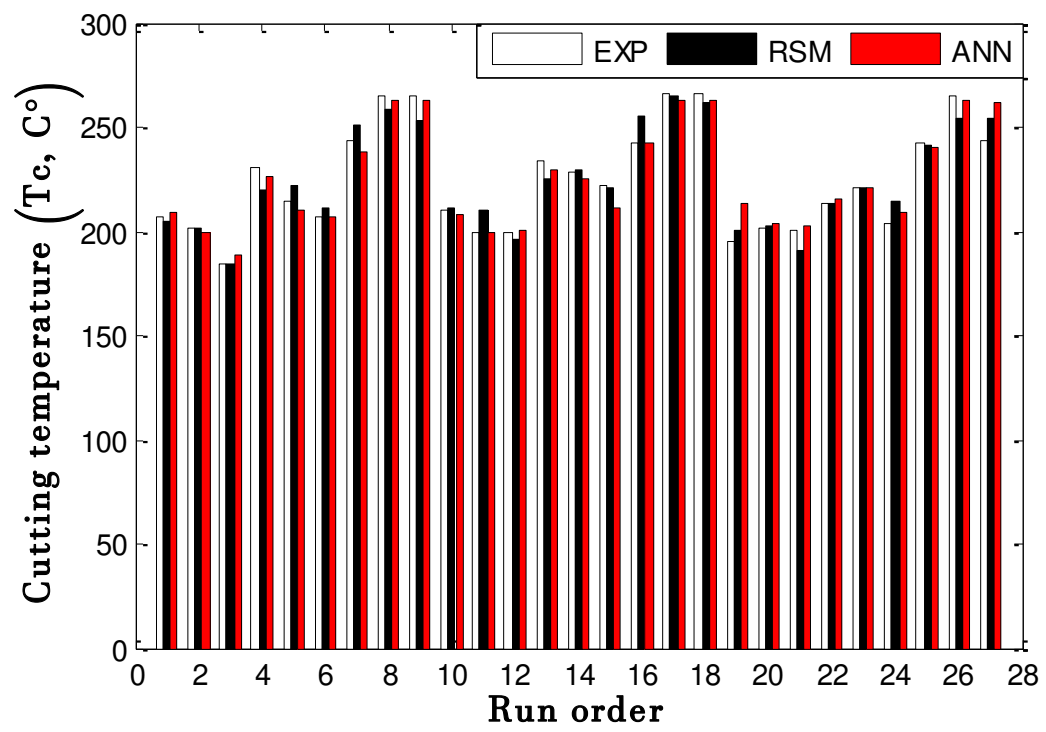




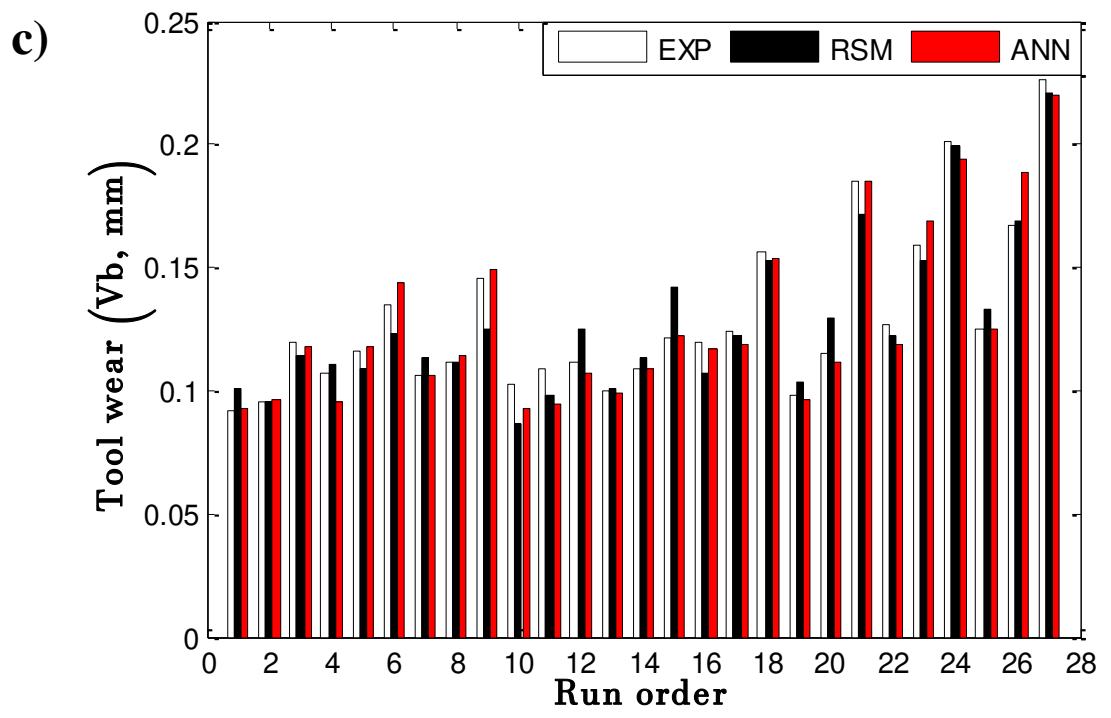

Figure 12. Comparison between the experimental and predicted results using ANN and RSM for: a) $R a, b) T_{C}$, c) $V_{B}$

Table 11. Comparison of prediction results for RSM and ANN

\begin{tabular}{|c|c|c|c|c|c|c|c|c|c|c|c|c|}
\hline \multirow[t]{2}{*}{ 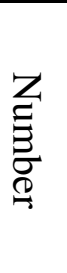 } & \multicolumn{2}{|c|}{$\begin{array}{l}\text { Predicted } \\
\text { Surface } \\
\text { roughness } \\
\quad(\mathrm{Ra})\end{array}$} & \multicolumn{2}{|c|}{$\begin{array}{l}\text { Absolute } \\
\text { prediction } \\
\text { error }(\%)\end{array}$} & \multicolumn{2}{|c|}{$\begin{array}{l}\text { Predicted } \\
\text { Tool flank } \\
\text { wear (VB) }\end{array}$} & \multicolumn{2}{|c|}{$\begin{array}{l}\text { Absolute } \\
\text { prediction } \\
\text { error }(\%)\end{array}$} & \multicolumn{2}{|c|}{$\begin{array}{l}\text { Predicted } \\
\text { Cutting } \\
\text { temperature } \\
\text { (TC) }\end{array}$} & \multicolumn{2}{|c|}{$\begin{array}{l}\text { Absolute } \\
\text { prediction } \\
\text { error }(\%)\end{array}$} \\
\hline & RSM & ANN & RSM & ANN & RSM & ANN & $\mathrm{RSM}$ & ANN & $\mathrm{RSM}$ & ANN & RSM & ANN \\
\hline 1 & 1,33 & 1,26 & $-1,88$ & $-7,35$ & 0,100 & 0,093 & 9,45 & 1,18 & 204,85 & 209,44 & $-1,12$ & 1,08 \\
\hline 2 & 2,36 & 2,47 & $-4,84$ & $-0,44$ & 0,095 & 0,096 & 0,84 & 1,62 & 201,58 & 199,34 & 0,02 & $-1,08$ \\
\hline 3 & 3,48 & 3,45 & $-0,65$ & $-1,31$ & 0,114 & 0,118 & $-4,58$ & $-1,54$ & 184,79 & 188,87 & 0,37 & 2,59 \\
\hline 4 & 1,35 & 1,32 & 4,13 & 1,6 & 0,110 & 0,095 & 3,36 & $-10,47$ & 220,19 & 226,13 & $-4,67$ & $-2,10$ \\
\hline 5 & 2,37 & 2,41 & $-3,66$ & $-2,23$ & 0,109 & 0,117 & $-5,77$ & 1,59 & 222,48 & 209,94 & 3,92 & $-1,93$ \\
\hline 6 & 3,47 & 3,54 & 1,84 & 3,93 & 0,123 & 0,144 & $-8,44$ & 6,67 & 211,26 & 207,50 & 1,91 & 0,09 \\
\hline 7 & 1,27 & 1,39 & $-3,96$ & 5,17 & 0,113 & 0,105 & 6,79 & $-0,13$ & 250,74 & 238,26 & 3,12 & $-2,00$ \\
\hline 8 & 2,27 & 2,11 & 9,40 & 1,35 & 0,111 & 0,114 & $-0,53$ & 1,83 & 258,61 & 263,00 & $-2,42$ & $-0,76$ \\
\hline 9 & 3,36 & 3,55 & $-5,26$ & 0,10 & 0,125 & 0,149 & $-14,24$ & 2,47 & 25296 & 263,15 & $-4,58$ & $-0,74$ \\
\hline 10 & 1,25 & 1,88 & 10,30 & 65,52 & 0,086 & 0,093 & $-15,63$ & $-9,63$ & 211,19 & 208,26 & 0,59 & $-0,80$ \\
\hline 11 & 2,25 & 2,30 & $-0,67$ & 1,63 & 0,098 & 0,094 & $-10,09$ & $-13,54$ & 210,21 & 199,95 & 5,22 & 0,09 \\
\hline 12 & 3,32 & 3,16 & 4,015 & $-0,83$ & 0,124 & 0,107 & 11,33 & $-4,00$ & 195,71 & 200,16 & $-1,63$ & 0,59 \\
\hline 13 & 1,34 & 1,26 & 2,97 & $-3,08$ & 0,100 & 0,098 & 0,6 & $-1,43$ & 225,40 & 229,65 & $-3,60$ & $-1,79$ \\
\hline 14 & 2,34 & 2,32 & 3,18 & 2,31 & 0,113 & 0,108 & 4,31 & $-0,36$ & 229,99 & 225,44 & 0,42 & $-1,56$ \\
\hline 15 & 3,43 & 3,47 & $-0,23$ & 1,02 & 0,142 & 0,121 & 17,60 & 0,76 & 221,07 & 211,32 & $-0,57$ & $-4,96$ \\
\hline 16 & 1,32 & 1,41 & $-10,39$ & $-4,71$ & 0,107 & 0,116 & $-10,83$ & $-2,65$ & 254,84 & 242,64 & 5,22 & 0,18 \\
\hline 17 & 2,34 & 2,29 & 2,34 & 0,22 & 0,122 & 0,118 & $-1,61$ & $-4,26$ & 265,00 & 263,37 & $-0,32$ & $-0,94$ \\
\hline
\end{tabular}




\begin{tabular}{ccccccccccccc}
\hline 18 & 3,44 & 3,55 & $-3,37$ & $-0,21$ & 0,152 & 0,154 & $-2,17$ & $-1,26$ & 261,65 & 262,70 & $-1,81$ & $-1,41$ \\
\hline 19 & 1,08 & 1,15 & $-3,41$ & 2,22 & 0,103 & 0,096 & 5,71 & $-1,25$ & 200,54 & 213,26 & 2,64 & 9,15 \\
\hline 20 & 2,02 & 1,91 & 4,96 & $-0,70$ & 0,129 & 0,111 & 12,78 & $-3,01$ & 202,43 & 203,40 & 0,57 & 1,06 \\
\hline 21 & 3,04 & 3,13 & $-3,71$ & $-0,89$ & 0,171 & 0,185 & $-7,35$ & 0,10 & 190,81 & 202,76 & $-4,92$ & 1,02 \\
\hline 22 & 1,25 & 1,26 & 0,94 & 2,13 & 0,122 & 0,118 & $-3,77$ & $-6,81$ & 213,36 & 215,38 & $-0,18$ & 0,76 \\
\hline 23 & 2,23 & 2,80 & $-12,55$ & 9,61 & 0,153 & 0,168 & $-3,64$ & 6,17 & 220,82 & 221,06 & 0,04 & 0,15 \\
\hline 24 & 3,30 & 3,16 & 5,79 & 1,35 & 0,199 & 0,194 & $-0,59$ & $-3,29$ & 214,78 & 209,00 & 5,26 & 2,43 \\
\hline 25 & 1,31 & 1,27 & 3,88 & 0,74 & 0,133 & 0,125 & 6,72 & 0,12 & 241,40 & 240,25 & $-0,58$ & $-1,05$ \\
\hline 26 & 2,34 & 2,23 & 5,88 & 0,88 & 0,169 & 0,188 & 1,37 & 13,02 & 254,44 & 263,33 & $-3,98$ & $-0,62$ \\
\hline 27 & 3,45 & 3,41 & 0,298 & $-0,90$ & 0,220 & 0,219 & $-2,30$ & $-2,72$ & 253,96 & 261,80 & 4,42 & 7,65 \\
\hline
\end{tabular}

\subsubsection{Multi-Response Optimization for $\mathrm{Ra}, \mathrm{V}_{\mathrm{B}}$ and $\mathrm{T}_{\mathrm{C}}$}

\section{Multi objective optimization using Desirability Function:}

The object of multi-response optimization is to determine the conditions on the independent variables that lead to optimal or nearly optimal values of the response variables.

Among different optimization approaches are available, one of them is the desirability function approach (DF). Due to its simplicity, effectiveness and sufficiently, its extensively employed by several experimenters ${ }^{[12,29,30,31]}$. For this reason, it is used in the current study. In DF, the operating conditions who have highest desirability value is considered as the optimal solution ${ }^{[32]}$. The equations to calculate the desirability are substantiated in Refs ${ }^{[29,33]}$. The asked objects and the variation interval of cutting parameters for optimization and its optimal result chosen are summarized in Tab. 12 and 13, respectively.

In this study, three cases of optimization were studied. Minimize surface roughness, cutting temperature and tool flank wear, respectively. Fig. 13, Fig. 14 displays desirability bar graph for the optimal solution. The parameter settings are presented in the first 3 bars and the optimal awaited response values are illustrated in the remaining bars. 
Table 12. Conditions and goals for the three optimization cases

\begin{tabular}{cccccccc}
\hline \multicolumn{7}{c}{ Conditions } \\
\hline Name & Unit & Goal & $\begin{array}{c}\text { Lower } \\
\text { limit }\end{array}$ & $\begin{array}{c}\text { Upper } \\
\text { limit }\end{array}$ & $\begin{array}{c}\text { Lower } \\
\text { weight }\end{array}$ & $\begin{array}{c}\text { Upper } \\
\text { weight }\end{array}$ & Importance \\
\hline $\mathrm{V}_{\mathrm{C}}$ & $\mathrm{m} / \mathrm{min}$ & In range & 200 & 425 & 1 & 1 & 3 \\
$\mathrm{~F}$ & $\mathrm{~mm} / \mathrm{rev}$ & In range & 0.12 & 0.24 & 1 & 1 & 3 \\
$\mathrm{Ap}$ & $\mathrm{mm}$ & In range & 0.15 & 0.45 & 1 & 1 & 3 \\
$\mathrm{Ra}$ & $\mu \mathrm{m}$ & Minimize & 1.126 & 3.56 & 1 & 1 & 5 \\
$\mathrm{~T}_{\mathrm{C}}$ & $\mathrm{C}^{\circ}$ & Minimize & 184.107 & 266.486 & 1 & 1 & 3 \\
$\mathrm{~V}_{\mathrm{B}}$ & $\mathrm{mm}$ & Minimize & 0.092 & 0.226 & 1 & 1 & 3 \\
\hline
\end{tabular}

Surface roughness represents manufacturing quality. The minimum value of surface roughness therefore indicates the good quality of surface finish. For this purpose, lower surface roughness is required to obtain the maximum importance.

\begin{tabular}{ccccccccc}
\hline & \multicolumn{10}{c}{ Solutions } \\
\hline Number & $\begin{array}{c}\mathrm{V}_{\mathrm{C}} \\
(\mathrm{m} / \mathrm{min})\end{array}$ & $\begin{array}{c}\mathrm{f} \\
(\mathrm{mm} / \mathrm{rev})\end{array}$ & $\begin{array}{c}\mathrm{Ap} \\
(\mathrm{mm})\end{array}$ & $\begin{array}{c}\mathrm{Ra} \\
(\boldsymbol{\mu m})\end{array}$ & $\begin{array}{c}\mathrm{T}_{\mathrm{C}} \\
\left(\mathrm{C}^{\circ}\right)\end{array}$ & $\begin{array}{c}\mathrm{V}_{\mathrm{B}} \\
(\mathrm{mm})\end{array}$ & Desirability & \\
\hline $\mathbf{1}$ & $\mathbf{4 2 5 , 0 0 0}$ & $\mathbf{0 , 1 2 0}$ & $\mathbf{0 , 1 5 0}$ & $\mathbf{1 , 0 9 5}$ & $\mathbf{1 9 5 , 3 7 7}$ & $\mathbf{0 , 1 0 5}$ & $\mathbf{0 , 9 3 5}$ & Selected \\
2 & 424,165 & 0,120 & 0,150 & 1,097 & 195,540 & 0,104 & 0,935 & \\
3 & 423,189 & 0,120 & 0,150 & 1,098 & 195,731 & 0,104 & 0,935 & \\
4 & 421,303 & 0,120 & 0,150 & 1,100 & 196,090 & 0,104 & 0,935 & \\
5 & 424,984 & 0,120 & 0,151 & 1,097 & 195,456 & 0,105 & 0,934 & \\
\hline
\end{tabular}

Table 13. Summary of solutions achieved for the five optimization cases
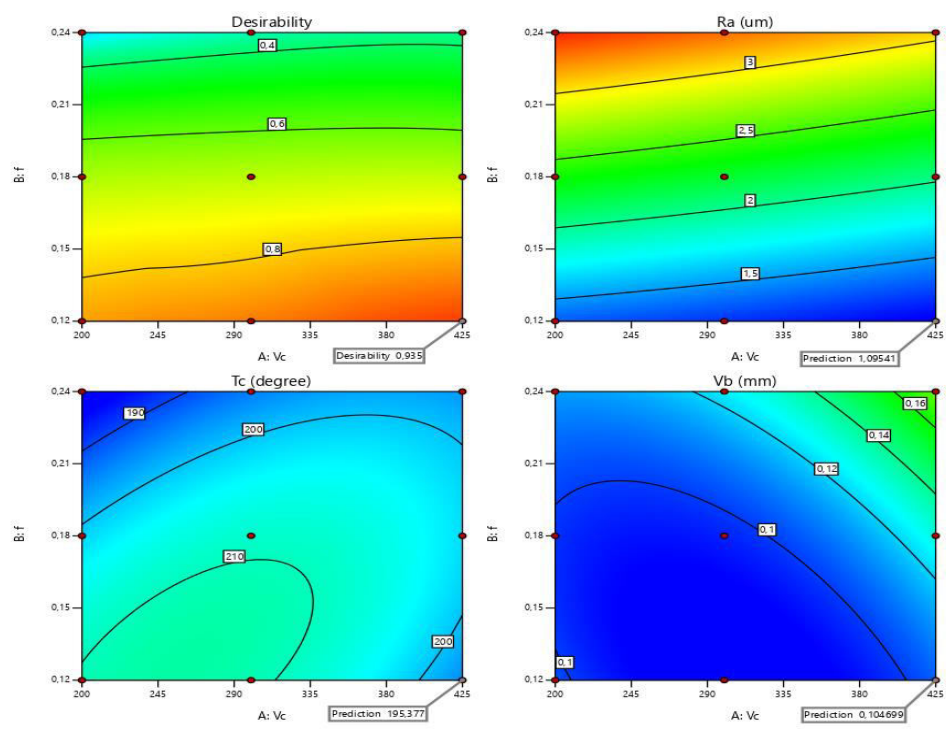
Figure 13. The graph plot of desirability. 


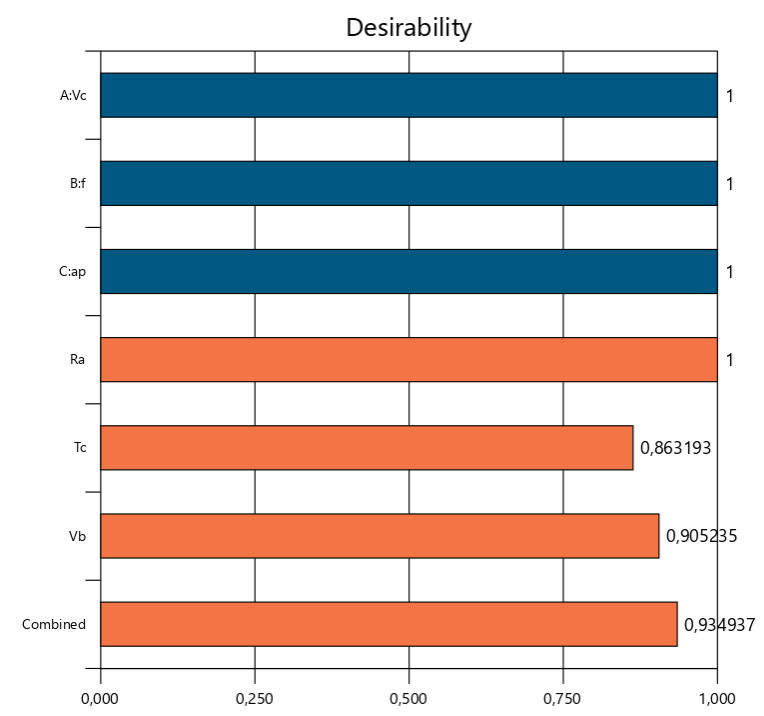

Figure 14. Desirability bar graph for the chosen optimization case.

\section{Multi objective optimization using Non-dominated Sorting Genetic Algorithm II}

The optimization of cutting parameters in machining has been the subject of several research works using various techniques. It allows the choice of the most suitable cutting conditions in order to obtain the desired results for the desired technological parameters. In this paper, advanced multi-objective optimization algorithm has been used to define the optimum sets that efficiently handles multi-objective optimization problems such as: the Second-Generation Evolutionary Algorithm (NSGA II) proposed by Deb et al. ${ }^{[34]}$.

NSGA II algorithm is one of the most cited classical algorithms in the field of evolutionary multi-objective optimization by SCI ${ }^{[35]}$. It reduces the computational complexity of the problem by introducing three algorithms: fast non-dominant sorting, elite strategy, and crowding distance sorting.

After processing, the obtained results with the ANN NSGA-II approach are found to be:

The optimum inputs are: feed rate $=0,12 \mathrm{~mm} / \mathrm{rev}$, depth of cut $=0,15 \mathrm{~mm}$ and cutting speed $=$ $424,96 \mathrm{~m} / \mathrm{min}$.

The optimum outputs are surface roughness $=1,87 \mu \mathrm{m}$, cutting temperature $=181,11 \mathrm{C}^{\circ}$ and tool flank wear $=0,095 \mathrm{~mm}$. 


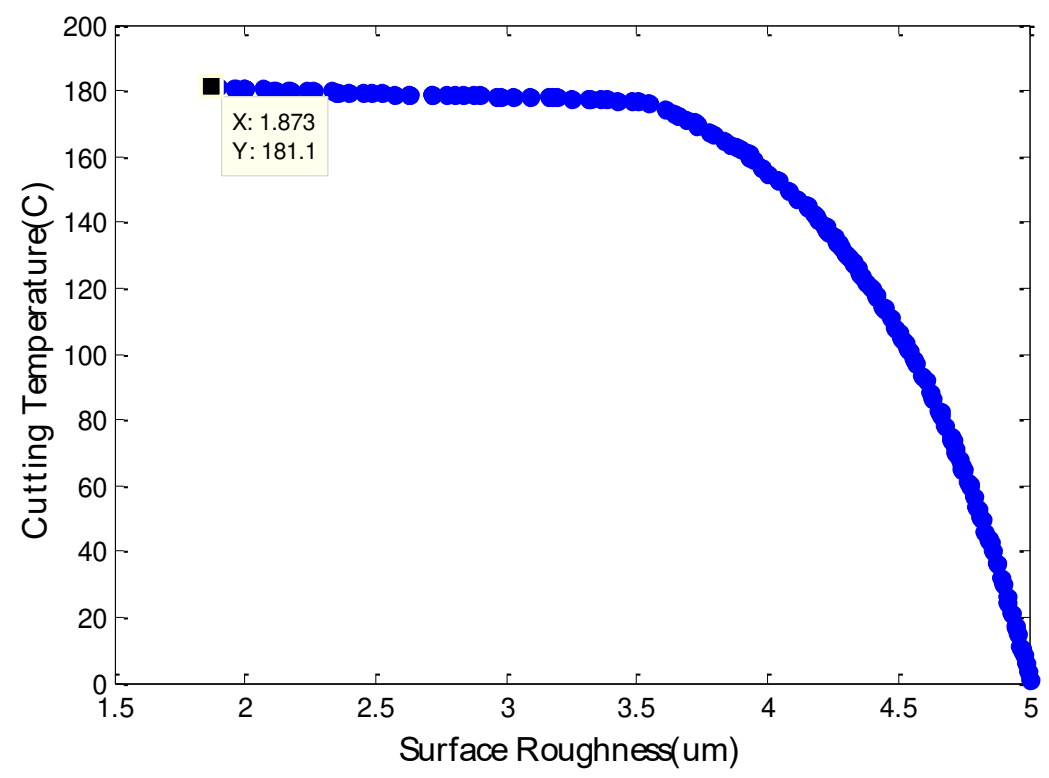

Figure 15. The Pareto curve for optimization of $\mathrm{T}_{\mathrm{C}}$ and $\mathrm{Ra}$ targets.

\subsubsection{Confirmation test results:}

The response surface methodology is a good modeling tool that helps in identifying the insignificant main factors and interaction factors or insignificant quadratic terms in the model which reduce the complexity of the problem and it helps also to achieve the best production control by multi optimization using desirability function. In the other side, the NGSA II algorithm the possibility to use ANN results giving more accuracy to the optimization process. The comparative study indicated that the desirability function solutions were found to be closer to the confirmation test results compared to those obtained by NGSA II as indicated in Tab. 14 and Fig. 16.

Table 14. Optimization results comparison.

\begin{tabular}{|c|c|c|c|c|}
\cline { 3 - 5 } \multicolumn{2}{c|}{} & $\begin{array}{c}\text { Multi Res. } \\
\text { Opt. }\end{array}$ & NSGA-II & Confirmation test \\
\hline \multirow{3}{*}{ Inputs } & $\mathrm{ap}(\mathrm{mm})$ & 0.15 & 0.15 & 0.15 \\
& $\mathrm{~V}_{\mathrm{C}}(\mathrm{m} / \mathrm{min})$ & 425 & 424.96 & 425 \\
& $\mathrm{f}(\mathrm{mm} / \mathrm{rev})$ & 0.12 & 0.12 & 0.12 \\
\hline \multirow{3}{*}{ Outputs } & $\mathrm{Ra}(\mathrm{m})$ & 1.095 & 1.87 & 1.126 \\
& $\mathrm{~T}_{\mathrm{C}}\left(\mathrm{C}^{\circ}\right)$ & 195.377 & 181.11 & 195.373 \\
& $\mathrm{~V}_{\mathrm{B}}(\mathrm{mm})$ & 0.105 & 0.095 & 0.098 \\
\hline
\end{tabular}




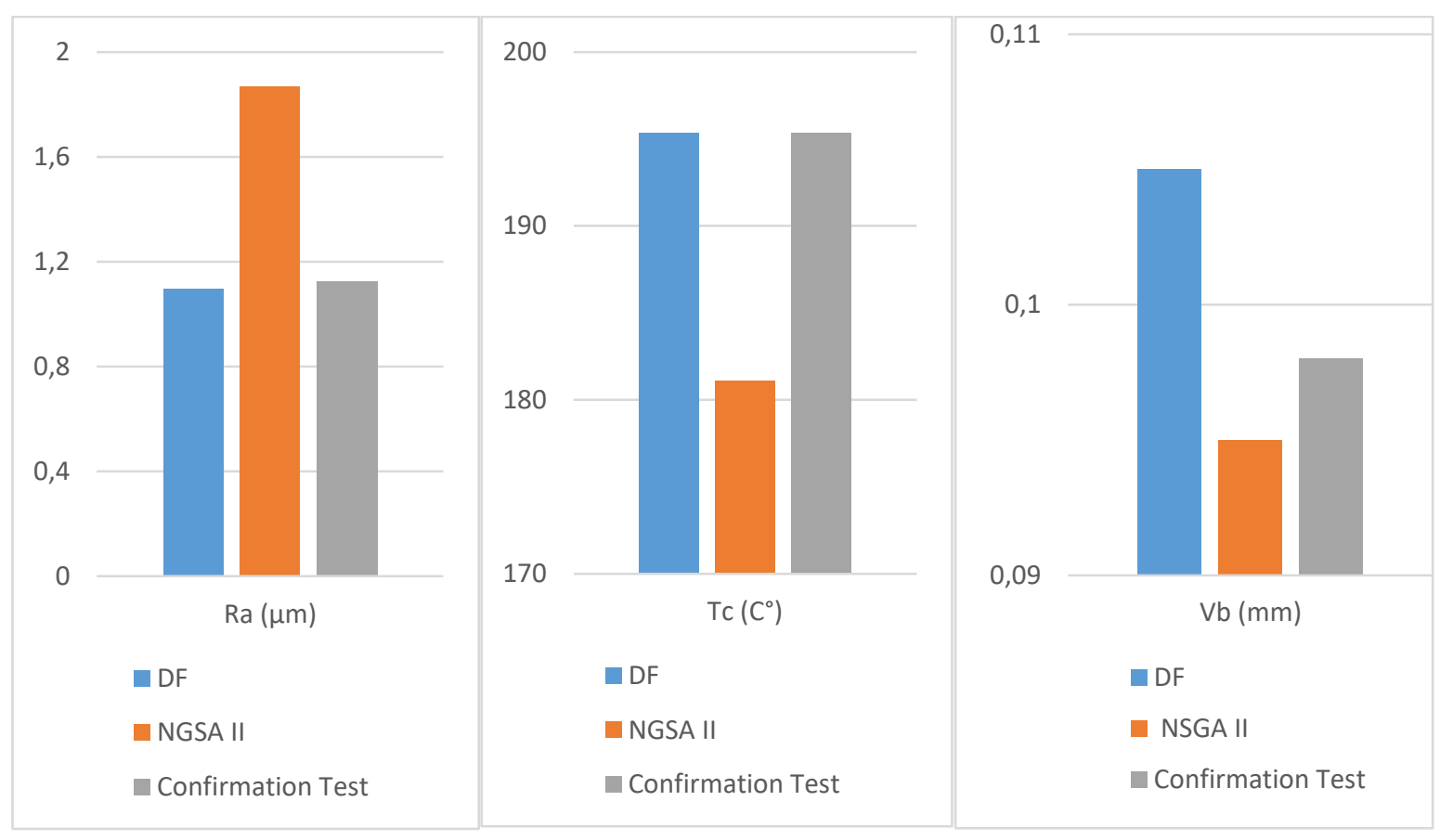

Figure 16. Optimization results comparison.

\section{Conclusion}

This study details the modeling and optimization of the dry-turning of AISI 316L machined by a coated carbide insert. It also compares the performance of both the response surface methodology (RSM) and the artificial neural network (ANN) according to their prediction and generalization capabilities using experimental results based on the Taguchi design for surface roughness, cutting temperature and tool flank wear. In addition, in this research work, the performance of DF is analysed and compared with NSGA-II. According to the results analysis, it has been found that:

1- Depth of cut is the dominant factor affecting the cutting temperature with proportion of the contribution of $78.26 \%$.

2- Statistical ANOVA confirmed that the feet rate (f) has the strongest influence on the surface roughness criteria. The proportion of the contribution is $92.64 \%$.

3- ANOVA of the tool flank wear indicated that the feed rate (f) is the factor that has the greatest influence on VB with contribution of $30.47 \%$. The Cutting speed (VC) comes second with contribution of $26.37 \%$. Finally, the depth of cut (ap) with a contribution of $9.59 \%$. 
4- The response surface methodology is a great modeling approaches that facilitates the problem and enables to identifying the significant and insignificant factors and their interaction on the desired response in a simple manner.

5- The comparative study indicated that the ANN models were found to be better in providing more accurate prediction results of surface roughness, cutting temperature and tool flank wear compared to RSM models in terms of better correlation and lower error.

6- The use of the DF for the optimization of several parameters simultaneously is considered very satisfactory to minimize the machining parameters $\mathrm{Ra}, \mathrm{VB}, \mathrm{TC}$.

7- The approach ANN-NGSA II was found to be helpful for future industrial application for predicting $\mathrm{Ra}, \mathrm{VB}, \mathrm{TC}$ with accurate results and optimizing the cutting parameters that helps as to achieve a best production control.

Acknowledgements: This work was achieved in the mechanic's laboratory (Frères Mentouri University, Constantine 1, Algeria) in cooperation with Mechanics Research Centre (CRM, Constantine, Algeria). The authors would like to thank the Algerian Ministry of Higher Education and Scientific Research (MESRS).

\section{Declarations}

Funding: The work is financed by the Algerian Ministry of Higher education and Scientific Research.

Conflicts of interest/Competing interests: I, Mr. Oussama BENKHELIFA, corresponding author of the paper, certify that we have no potential conflict of interest for the presented article

Availability of data and material: Not applicable

Code availability: Not applicable

Authors' contributions: (optional)

Additional declarations for articles in life science journals that report the results of studies involving humans and/or animals: Not applicable

Ethics approval: I certify that the paper follows the ethical rules of good scientific practice mentioned in the "Ethical Responsibilities of Authors" of the journal. 
Consent to participate (include appropriate statements): Not applicable

\section{Consent for publication (include appropriate statements)}

Oussama BENKHELIFA hereby declare that I participated in the study and in the development of the manuscript and authorize the full the publishing of manuscript data.

\section{References}

[1] TOUGGUI, Youssef, BELHADI, Salim, MECHRAOUI, Salah-Eddine, et al. Statistical study and multi-response optimization of cutting parameters for dry turning stainless steel AISI 316L using cermet tool. In: Advanced Engineering Forum. Trans Tech Publications Ltd, 2020. p. 28-46.

[2] NUR, Rusdi, NOORDIN, M. Y., IZMAN, S., et al. Machining parameters effect in dry turning of AISI 316L stainless steel using coated carbide tools. Proceedings of the Institution of Mechanical Engineers, Part E: Journal of Process Mechanical Engineering, 2017, vol. 231, no 4, p. 676-683.

[3] MARTOWIBOWO, Sigit Yoewono, KEMALA DAMANIK, Bivynka, et al. Optimization of Material Removal Rate and Surface Roughness of AISI 316L under Dry Turning Process using Genetic Algorithm. Manufacturing Technology, 2021, vol. 21, no 3, p. 373-380.

[4] AKBAR, Ahmed A., SHWAISH, Raed R., et HADI, Naba D. Study the Effect of Cutting Parameters on Temperature Distribution and Tool Life During Turning Stainless Steel 316L. Al-Khwarizmi Engineering Journal, 2018, vol. 14, no 3, p. 112-122.

[5] SINGH, Amarjit et SINHA, Manoj Kumar. Multi-Response Optimization during Dry Turning of Bio-Implant Steel (AISI 316L) Using Coated Carbide Inserts. Arabian Journal for Science and Engineering, 2020, vol. 45, no 11, p. 9397-9411.

[6] RODRÍGUEZ, Jesús, MUÑOZ-ESCALONA, Patricia, et CASSIER, Zulay. Influence of cutting parameters and material properties on cutting temperature when turning stainless steel. Revista de la Facultad de Ingeniería Universidad Central de Venezuela, 2011, vol. 26, no 1, p. 71-80. 

machining parameters in CNC turning of AISI 3161 stainless steel using MQL nano fluids. In: IOP Conference Series: Materials Science and Engineering. IOP Publishing, 2018. p. 012049.

ZAHARUDIN, A. M. et BUDIN, S. Influence of cutting speed on coated TiCN cutting tool during turning of AISI 316L stainless steel in dry turning process. In: IOP Conference Series: Materials Science and Engineering. IOP Publishing, 2019. p. 012044.

[9] PRASAD, Balla Srinivasa, PRABHA, K. Aruna, et KUMAR, PVS Ganesh. Condition monitoring of turning process using infrared thermography technique-An experimental approach. Infrared Physics \& Technology, 2017, vol. 81, p. 137-147. ASILTÜRK, Ilhan et NEŞELI, Süleyman. Multi response optimisation of CNC turning parameters via Taguchi method-based response surface analysis. Measurement, 2012, vol. 45, no 4, p. 785-794.

[11] NIKOLAOS, I. Galanis, and DIMITRIOS, Manolakos. Surface roughness prediction in turning of femoral head. The International Journal of Advanced Manufacturing Technology, 2010, Vol. 51, Issue 1, pp. 79-86. ISSN : 0268-3768. DOI : 10.1007/s00170010-2616-4.

[12] CHABBI, A., YAlleSE, M. A., NOUiOUA, M., et al. Modeling and optimization of turning process parameters during the cutting of polymer (POM C) based on RSM, ANN, and DF methods. The International Journal of Advanced Manufacturing Technology, 2017, vol. 91, no 5, p. 2267-2290.

[13] PARIDA, Asit Kumar et MAITY, Kalipada. Modeling of machining parameters affecting flank wear and surface roughness in hot turning of Monel-400 using response surface methodology (RSM). Measurement, 2019, vol. 137, p. 375-381.

[14] DAS, Biswajit, ROY, Susmita, RAI, R. N., et al. Studies on effect of cutting parameters on surface roughness of al-Cu-TiC MMCs: an artificial neural network approach. Procedia Computer Science, 2015, vol. 45, p. 745-752. 
machining parameters to minimize surface roughness using integrated ANN-GA approach. Procedia Cirp, 2015, vol. 29, p. 305-310.

[16] NOUIOUA, Mourad, LAOUISSI, Aissa, YALLESE, Mohamed Athmane, et al. Multi-response optimization using artificial neural network-based GWO algorithm for high machining performance with minimum quantity lubrication. The International Journal of Advanced Manufacturing Technology, 2021, vol. 116, no 11, p. 3765-3778.

[17] MORALES TAMAYO, Yoandrys, BELTRÁN REYNA, Roberto Félix, LÓPEZ BUSTAMANTE, Ringo John, et al. Comparison of two methods for predicting surface roughness in turning stainless steel AISI 316L. Ingeniare. Revista chilena de ingeniería, 2018, vol. 26, no 1, p. 97-105.

[18] ASILTÜRK, Ilhan et ÇUNKAŞ, Mehmet. Modeling and prediction of surface roughness in turning operations using artificial neural network and multiple regression method. Expert systems with applications, 2011, vol. 38, no 5, p. 5826-5832.

[19] Kara F, Aslantas K and Çiçek A. ANN and multiple regression method-based modelling of cutting forces in orthogonal machining of AISI 316L stainless steel. Neural Comput Appl, 2015, 2, p. 237-250.

[20] NOUIOUA, Mourad, YALlESE, Mohamed Athmane, KHETTABI, Riad, et al. Investigation of the performance of the MQL, dry, and wet turning by response surface methodology (RSM) and artificial neural network (ANN). The International Journal of Advanced Manufacturing Technology, 2017, vol. 93, no 5, p. 2485-2504.

[21] KILICKAP, Erol, YARDIMEDEN, Ahmet, et ÇELIK, Yahya Hışman. Mathematical modelling and optimization of cutting force, tool wear and surface roughness by using artificial neural network and response surface methodology in milling of Ti6242S. Applied Sciences, 2017, vol. 7, no 10, p. 1064.

[22] ZERTI, Abderrahmen, YALLESE, Mohamed Athmane, ZERTI, Oussama, et al. Prediction of machining performance using RSM and ANN models in hard turning of martensitic stainless steel AISI 420. Proceedings of the Institution of Mechanical Engineers, Part C: Journal of Mechanical Engineering Science, 2019, vol. 233, no 13, p. 4439-4462. 
[23] Seco Tools catalogue 2019.

[24] BAGABER, Salem Abdullah et YUSOFF, Ahmed Razlan. Multi-objective optimization of cutting parameters to minimize power consumption in dry turning of stainless steel 316. Journal of cleaner production, 2017, vol. 157, p. 30-46.

[25] CHOU, Y. K. et BARASH, M. M. Review on hard turning and CBN cutting tools, 1st Int. In: Machining and Grinding Conference, SME Technical Paper MR. 1995. p. 95-214.

[26] KHURI, André I. et MUKHOPADHYAY, Siuli. Response surface methodology. Wiley Interdisciplinary Reviews: Computational Statistics, 2010, vol. 2, no 2, p. 128-149.

[27] MIA, Mozammel. Mathematical modeling and optimization of MQL assisted end milling characteristics based on RSM and Taguchi method. Measurement, 2018, vol. 121, p. 249-260.

[28] KUMAR, Pardeep et CHAUHAN, S. R. Machinability study on finish turning of AISI H13 hot working die tool steel with cubic boron nitride (CBN) cutting tool inserts using response surface methodology (RSM). Arabian Journal for Science and Engineering, 2015, vol. 40, no 5, p. 1471-1485.

[29] ZERTI, Abderrahmen, YALLESE, M. A., MEDDOUR, Ikhlas, et al. Modeling and

multi-objective optimization for minimizing surface roughness, cutting force, and power, and maximizing productivity for tempered stainless steel AISI 420 in turning operations. The International Journal of Advanced Manufacturing Technology, 2019, vol. 102, no 1, p. 135157.

[30] BENSOUILAH, Hamza, AOUICI, Hamdi, MEDDOUR, Ikhlas, et al. Performance

of coated and uncoated mixed ceramic tools in hard turning process. Measurement, 2016, vol. 82 , p. $1-18$.

[31] ZAHIA, Hessainia, ATHMANE, Y., LAKHDAR, Bouzid, et al. On the application

of response surface methodology for predicting and optimizing surface roughness and cutting 
forces in hard turning by PVD coated insert. International Journal of Industrial Engineering Computations, 2015, vol. 6, no 2, p. 267-284.

[32] GOPALAKANNAN, S. et SENTHILVELAN, T. Application of response surface method on machining of Al-SiC nano-composites. Measurement, 2013, vol. 46, no 8, p. 2705-

2715.

[33] LAOUISSI, A., YALLESE, M. A., BELBAH, A., et al. Comparative study of the performance of coated and uncoated silicon nitride ( $\mathrm{Si} 3 \mathrm{~N}$ 4) ceramics when machining ENGJL-250 cast iron using the RSM method and 2D and 3D roughness functional parameters. Journal of the Brazilian Society of Mechanical Sciences and Engineering, 2019, vol. 41, no 5, p. 1-23.

[34] DEB, Kalyanmoy, PRATAP, Amrit, AGARWAL, Sameer, et al. A fast and elitist multiobjective genetic algorithm: NSGA-II. IEEE transactions on evolutionary computation, 2002, vol. 6, no 2, p. 182-197.

[35] GONG, Maoguo, JIAO, Licheng, DU, Haifeng, et al. Multi-objective immune algorithm with nondominated neighbor-based selection. Evolutionary computation, 2008, vol. 16, no 2, p. 225-255. 